
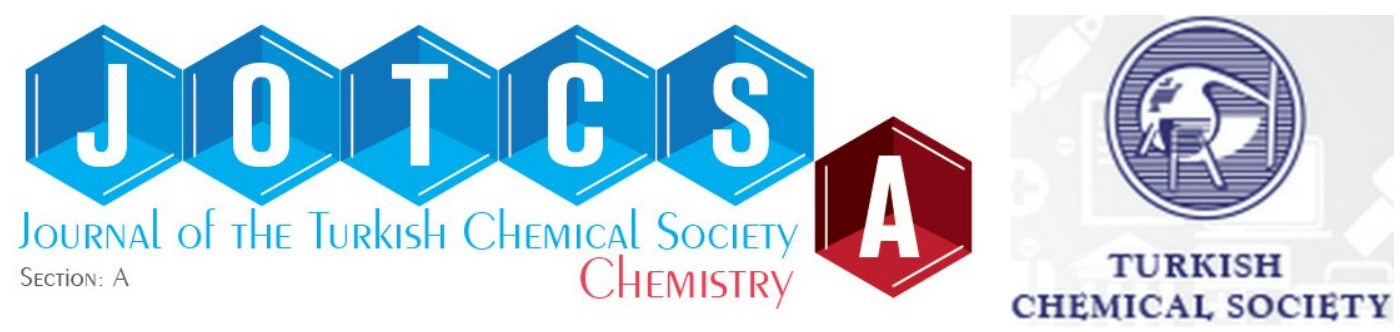

\title{
Box Behnken Design in the Optimization of Rhodamine B Adsorption onto Activated Carbon Prepared from Delonix regia Seeds and Pods
}

\author{
Samsudeen Olanrewaju Azeez ${ }^{1 *}$ D, Ismaila Olalekan Saheed ${ }^{1}$ (D), \\ Folahan Amoo Adekola² (D), Akeem Adebayo Jimoh ${ }^{1}$ (D), David Morakinyo Aransiola' \\ and Zuliah A. Abdulsalam ${ }^{1}$
}

\begin{abstract}
${ }^{1}$ Kwara State University, Faculty of Pure and Applied Sciences, Department of Chemistry and Industrial Chemistry, 241103, Malete, Nigeria.

${ }^{2}$ University of Ilorin, Faculty of Physical Sciences,Department of Industrial Chemistry, 240003, Ilorin, Nigeria
\end{abstract}

Abstract: The uptake of Rhodamine B (RhB) dye onto chemically prepared activated carbon from
Delonix regia pods (DPAC) and seeds (DSAC) by response surface methodology was investigated. The
activated carbons were prepared with $1 \mathrm{M}$ nitric acid and characterized by BET FTIR, SEM and EDX. The
results obtained revealed that the prepared activated carbons DPAC and DSAC with pore diameter 4.04
$\mathrm{~nm}$ and $3.48 \mathrm{~nm}$ respectively possess mesoporous structures. Optimization of the four operating
variables viz; concentration, adsorbent dosage, contact time, and pH on RhB adsorption were examined
using Box Behnken design (BBD). The maximum removal efficiency of RhB from aqueous solution was
achieved at $99.16 \%$ and $98.36 \%$ for DSAC and DPAC respectively with an initial RhB concentration of 55
$\mathrm{mg} / \mathrm{L}, 0.1 \mathrm{~g}$ dosage, pH 12, and $725 \mathrm{~min}$ for both adsorbents. The actual values of $99.16 \%$ (DSAC) and
$98.36 \%$ (DPAC) compared with predicted values $101.7 \%$ (DSAC) and $99.40 \%$ (DPAC) have a good
agreement and this confirms the suitability of the proposed model. The adsorption process fitted best
into the Freundlich isotherm model. The adsorption process was adequately described by the pseudo-
second-order kinetics model. Intra-particle diffusion appears to control the adsorption process but is not
the only rate-limiting step.

Keywords: Delonix regia, Activated carbon, Box Behnken Design, Adsorption isotherm, Rhodamine B

Submitted: March 15, 2021. Accepted: January 07, 2022.

Cite this: Azeez SO, Saheed IO, Adekola FA, Jimoh AA, Aransiola DM, Abdulsalam ZA. Box Behnken Design in the Optimization of Rhodamine B Adsorption onto Activated Carbon Prepared from Delonix regia Seeds and Pods. JOTCSA. 2022;9(1):205-22.

DOI: https://doi.org/10.18596/jotcsa.893472.

*Corresponding author. E-mail: samsudeen.azeez@kwasu.edu.ng.

\section{INTRODUCTION}

Out of several synthetic dyes, rhodamine B remains one of the prominent, unavoidably dangerous, and more functional organic dyes used largely in textile and paper industries. It is applied in the cell membrane and water tracing studies (1). This is as a result of its high water solubility and photo-stability. However, it creates a severe environmental problem due to its toxicity to human and aquatic lives when discharged into the environment. The presence of this dye in water bodies decreases light penetration and thus disrupts the photosynthetic processes $(2,3)$. In extreme cases, it causes cancer $(4,5)$. Consequently, it is imperative to treat wastewater containing this dye before its release into the environment for human and aquatic safety. Many treatment methods had been put into consideration for the removal of dyestuff from 
wastewater such as oxidation (6), photochemical degradation (7), electrochemical degradation (8), and membrane separation (9). Though most of the aforementioned treatment methods for separating dyes from dye-containing wastewater have great limitations which include exorbitant, less effectiveness, production of toxic materials, and high energy demands (10). However, adsorption as a treatment technique employing activated carbon is immensely gaining worldwide acceptance for removing dyes and other organic pollutants from aqueous solutions owing to its ease of operation, low cost, simple design, and regeneration $(11,12)$. Furthermore, there has been much interest in the creation of new and more effective materials for organic pollutants removal knowing that commercial activated carbon which is the most extensively used adsorbent is expensive (13). Hence there is a need for the evolution of natural, more accessible, and low-priced activated carbon adsorbents from agricultural wastes such as Delonix regia pods and seeds for dye removal.

Delonix regia, a flame tree also known as flamboyant tree aboriginal to Madagascar but commonly planted in the tropics. It is a flowering plant belonging to the Fabaceae family and subfamily Caesalpinioideae. It is grown as an ornamental tree in parks, gardens, school compounds, and residential for shades and shelter. In English, it is regarded as Royal Poinciana or Flamboyant also called Pansheke in the Yoruba language which is one of the major tribes in Nigeria. The pods and seeds of Delonix regia are non-edible and as such regarded as agricultural wastes except for the aesthetic purposes of the tree (14).

The optimization parameters were designed based on the factorial design of experiments and analyzed statistically. The experimental design technique is a useful tool to study biodegradation and adsorption because it provides statistical models that help in elucidating the interactions among the parameters that have been optimized $(15,16)$. Furthermore, they are important for systematic investigations which require a few experiments and also help to interpret results meaningfully. Response surface methodology (RSM) is a factorial design based on the statistical analyzing method. It is used for designing experiments, studying the effective factors, and searching for the optimum conditions $(17,18)$. The most commonly used designs in RSM are Box Behnken design (BBD) and Central Composite Design (CCD). However, BBD is agreed to be an effective and efficient design in RSM to CCD (19). This model was widely accepted in industries such as the food and drug industry, biological and chemical processes, enhancing the production of quality products and reduction in the cost of the operation $(16,20)$. This technique has been usefully employed in many operating processes for achieving its optimization. The basis of this investigation is to prepare and characterize a lowcost activated carbon from Delonix regia pods and seeds via acid treatment and its employment in the adsorption of Rhodamine $B$ in aqueous media using Box Behnken Design (BBD) in response surface methodology (RSM) to optimize the operating parameters such as concentration, $\mathrm{pH}$, adsorbent dosage and contact time.

\section{EXPERIMENTAL SECTION}

\section{Chemicals and Apparatus}

The reagents and chemicals for this experiment were of analytical grade and used directly with no further purifications. Rhodamine $B$ was purchased from BDH (Prolabo, Leuven Belgium), sodium hydroxide $(\mathrm{NaOH})$, nitric acid $\left(\mathrm{HNO}_{3}, \geq 90.0 \%\right)$, hydrochloric acid $(\mathrm{HCl}, 37 \%)$ were all supplied by Sigma Aldrich, USA. The apparatus used are BET surface area analyzer (Micromeritics ASAP 2020 V3.02H model, Norcross, GA, U.S.A), UV/Visible spectrophotometer (Bechman Coulter DU 730 Pasadena, CA, USA), Perkin-Elmer Spectrum GXFTIR Spectrometer (version 10.6 0, TU, Dublin), SEM/EDX ASPEX 3020 model (Delmont, PA 156261723-USA).

\section{Sample collection and preparation of Adsorbent}

The Delonix regia pods and seeds were obtained from Kwara State University, Malete, Nigeria. The seeds were separated from the pods, handpicked to remove sands, and washed thoroughly to remove dust particles. Then sundried, and the pods crushed into smaller sizes. The seeds and pods of Delonix regia were carbonized separately at the temperature of $500{ }^{\circ} \mathrm{C}$ and $400{ }^{\circ} \mathrm{C}$ respectively for $180 \mathrm{~min}$. Activation of the carbonized products was done after pulverizing using nitric acid: which involves impregnating 100 $\mathrm{g}$ of both the carbonized seeds and pods into 500 $\mathrm{mL}$ of $1 \mathrm{M} \mathrm{HNO}_{3}$ in a separate beaker and stirring for $24 \mathrm{~h}$. The resulting activated carbon was filtered and washed with deionized water to neutrality and dried in the oven at $110{ }^{\circ} \mathrm{C}$ to remove all moisture components. Thereafter, the Delonix regia seeds activated carbon (DSAC) and Delonix regia pods activated carbon (DPAC) were ground and sieved into $<63 \mu \mathrm{m}$ mesh size (21).

\section{Characterization of the adsorbents}

The surface area of the adsorbents (DSAC and DPAC) was determined by Brunauer, Emmett and Teller (BET) analysis of $\mathrm{N}_{2}$ adsorption at $77 \mathrm{~K}$ by the use of Micromeritics ASAP 2020 V3.02H model. The functional groups present on the adsorbents were investigated by Fourier Transform Infrared Spectrometer (Perkin-Elmer Spectrum GX). The 
morphologies and elemental composition of DSAC and DPAC were analyzed using SEM, ASPEX 3020 model for SEM and EDX respectively.

\section{Preparation of adsorbate}

A $1000 \mathrm{mg} / \mathrm{L}$ of rhodamine B dye (RhB) stock solution was prepared by dissolving $1 \mathrm{~g}$ of the dye in $1 \mathrm{~L}$ of deionized water in a standard volumetric flask. The working solutions were then prepared from the stock via serial dilution (11).

\section{Adsorption experiments}

The batch adsorption method was used to investigate the initial RhB dye concentration, effects of $\mathrm{pH}$, contact time, and adsorbent dosage. The experiment entails the addition of $0.1 \mathrm{~g}$ of DSAC and DPAC to $20 \mathrm{~mL}$ of $\mathrm{RhB}$ solution of desired concentrations in a $100 \mathrm{~mL}$ conical flask and placed in a temperature-controlled water bath shaker. The solutions were agitated for $2 \mathrm{~h}$ at a temperature of $28 \pm 2{ }^{\circ} \mathrm{C}$ and a speed of $180 \mathrm{rpm}$. $0.1 \mathrm{M} \mathrm{HCl}$ and $0.1 \mathrm{M} \mathrm{NaOH}$ solutions were used to control the $\mathrm{pH}$ of the solution. The resultant mixture was then centrifuged and filtered. Thereafter, the change in concentration of the RhB solution was monitored using a UV/Visible spectrophotometer (Bechman Coulter DU 730 Pasadena, CA, USA) operated at a maximum wavelength $\left(\lambda_{\max }\right)$ of $554 \mathrm{~nm}$. The influence of operational parameters such as contact time, $\mathrm{pH}$, and adsorbent dosage was studied. The \% of RhB removed was measured by Equation $1(11,21)$.

$$
\text { \%adsorbed }=\frac{\left(C_{0}-C_{e}\right)}{C_{0}} \times 100 \text { (Eq. 1) }
$$

where, $\mathrm{Co}=$ initial $\mathrm{RhB}$ dye concentration $(\mathrm{mg} / \mathrm{L})$ and $\mathrm{Ce}=$ equilibrium $\mathrm{RhB}$ dye concentration (mg/L).

\section{Optimization of operating parameters of the adsorption process}

The optimization experimental parameters of the adsorption process of RhB by activated carbon prepared from DSAC and DPAC were ascertained by Box Behnken Design (BBD) under response surface methodology (RSM). The design was employed to generate sets of designed experiments using Design Expert 11.1.2.0 with four factors; concentration (A), adsorbent dosage $(B), \mathrm{pH}(\mathrm{C})$, and contact time (D) based on a fourlevel full or fractional factorial design with an incomplete block design of experiments and were analyzed statistically. Comprehensively, specific numbers of factors are fixed in between all combinations in each design block, but other factors are kept at the central values $(16,17)$. The BBD has four variables which were varied at two levels that is, low $(-1)$ and high $(+1)$ with 29 experimental runs. The responses were presented as the adsorption efficiency (\%). Table 1 and 2 shows the experimental runs and variables. The experimental data were analyzed and fit the quadratic model which describes the nature of the process as expressed by the empirical equation in Equation 2.

$$
H=\beta_{0}+\sum_{i=1}^{k} \beta_{i} x_{i}+\sum_{i=1}^{k} \beta_{i i} x_{i}^{2}+\sum_{1 \leq i \leq j}^{k} \beta_{i j} x_{i} x_{j}+\epsilon \text { (Eq. 2) }
$$

Where, $H$ is the response; $x_{i}=$ variables; $k=$ number of variables; $\beta_{0}=$ constant term; $\beta_{i}=$ coefficients of linear parameters, $\beta_{i j}=$ coefficient of the interaction parameters; $\beta_{i i}=$ coefficient of the quadratic parameter; $\varepsilon=$ residual associated to the experiments.

\begin{tabular}{|c|c|c|c|c|c|c|}
\hline \multirow{2}{*}{$\begin{array}{l}\text { Experimental } \\
\text { run }\end{array}$} & \multicolumn{4}{|c|}{ Independent variables } & \multicolumn{2}{|c|}{ Response (\%) } \\
\hline & $\begin{array}{l}(\mathrm{A}) \\
\text { Concentratio } \\
\mathrm{n} \\
(\mathrm{mg} / \mathrm{L})\end{array}$ & $\begin{array}{l}\text { (B )Dose } \\
\text { (g) }\end{array}$ & $\begin{array}{l}\text { (C) Time } \\
\text { (min) }\end{array}$ & (D) $\mathrm{pH}$ & $\begin{array}{l}\text { Actual } \\
\text { removal }\end{array}$ & $\begin{array}{l}\text { Predicted } \\
\text { removal }\end{array}$ \\
\hline 1 & 100 & 0.4 & 725 & 12 & 98.70 & 98.96 \\
\hline 2 & 55 & 0.4 & 1440 & 12 & 98.50 & 97.16 \\
\hline 3 & 55 & 0.4 & 10 & 2 & 89.51 & 90.64 \\
\hline 4 & 55 & 0.4 & 725 & 7 & 97.85 & 98.05 \\
\hline 5 & 55 & 0.7 & 725 & 2 & 94.40 & 92.47 \\
\hline 6 & 100 & 0.4 & 1440 & 7 & 98.50 & 97.23 \\
\hline 7 & 10 & 0.4 & 725 & 12 & 87.91 & 87.80 \\
\hline 8 & 55 & 0.4 & 725 & 7 & 98.00 & 98.05 \\
\hline 9 & 55 & 0.7 & 725 & 12 & 95.85 & 95.25 \\
\hline 10 & 10 & 0.4 & 10 & 7 & 79.63 & 81.51 \\
\hline 11 & 55 & 0.4 & 1440 & 2 & 97.85 & 98.40 \\
\hline 12 & 100 & 0.7 & 725 & 7 & 94.30 & 95.23 \\
\hline
\end{tabular}

Table 1: Box Behnken Design and its Actual and Predicted Values for DSAC. 


\begin{tabular}{lllllll}
13 & 55 & 0.1 & 1440 & 7 & 99.05 & 99.42 \\
14 & 55 & 0.4 & 10 & 12 & 97.12 & 96.36 \\
15 & 55 & 0.1 & 10 & 7 & 99.12 & 96.71 \\
16 & 10 & 0.7 & 725 & 7 & 79.83 & 80.18 \\
17 & 10 & 0.4 & 725 & 2 & 85.93 & 85.27 \\
18 & 100 & 0.4 & 10 & 7 & 92.25 & 93.18 \\
19 & 100 & 0.1 & 725 & 7 & 99.18 & 98.61 \\
20 & 55 & 0.1 & 725 & 12 & 99.16 & 101.70 \\
21 & 55 & 0.7 & 10 & 7 & 88.93 & 88.16 \\
22 & 55 & 0.4 & 725 & 7 & 97.97 & 98.05 \\
23 & 10 & 0.1 & 725 & 7 & 91.90 & 90.76 \\
24 & 55 & 0.4 & 725 & 7 & 98.65 & 98.05 \\
25 & 55 & 0.7 & 1440 & 7 & 92.00 & 94.01 \\
26 & 55 & 0.1 & 725.78 & 99.99 \\
27 & 10 & 0.4 & 1440 & 7 & 86.33 & 86.01 \\
28 & 100 & 0.4 & 725 & 2 & 97.30 & 97.01 \\
29 & 55 & 0.4 & 725 & 7 & 97.77 & 98.05 \\
\hline
\end{tabular}

Table 2: Box Behnken Design and its Actual and Predicted Values for DPAC.

\begin{tabular}{|c|c|c|c|c|c|c|}
\hline \multirow{2}{*}{$\begin{array}{l}\text { Experimental } \\
\text { runs }\end{array}$} & \multicolumn{4}{|c|}{ Independent variables } & \multicolumn{2}{|c|}{ Response (\%) } \\
\hline & $\begin{array}{l}(\mathrm{A}) \\
\text { Concentration } \\
(\mathrm{mg} / \mathrm{L})\end{array}$ & $\begin{array}{l}\text { (B )Dose } \\
\text { (g) }\end{array}$ & $\begin{array}{l}\text { (C) Time } \\
\text { (min) }\end{array}$ & (D) $\mathrm{pH}$ & $\begin{array}{l}\text { Actual } \\
\text { removal }\end{array}$ & $\begin{array}{l}\text { Predicted } \\
\text { removal }\end{array}$ \\
\hline 1 & 100 & 0.4 & 725 & 12 & 97.25 & 95.99 \\
\hline 2 & 55 & 0.4 & 1440 & 12 & 97.57 & 96.75 \\
\hline 3 & 55 & 0.4 & 10 & 2 & 92.42 & 91.40 \\
\hline 4 & 55 & 0.4 & 725 & 7 & 97.08 & 97.14 \\
\hline 5 & 55 & 0.7 & 725 & 2 & 90.23 & 89.30 \\
\hline 6 & 100 & 0.4 & 1440 & 7 & 97.77 & 97.91 \\
\hline 7 & 10 & 0.4 & 725 & 12 & 88.80 & 89.16 \\
\hline 8 & 55 & 0.4 & 725 & 7 & 97.93 & 97.14 \\
\hline 9 & 55 & 0.7 & 725 & 12 & 88.97 & 90.51 \\
\hline 10 & 10 & 0.4 & 10 & 7 & 82.33 & 82.30 \\
\hline 11 & 55 & 0.4 & 1440 & 2 & 97.60 & 96.61 \\
\hline 12 & 100 & 0.7 & 725 & 7 & 96.08 & 95.59 \\
\hline 13 & 55 & 0.1 & 1440 & 7 & 98.02 & 99.54 \\
\hline 14 & 55 & 0.4 & 10 & 12 & 95.85 & 94.99 \\
\hline 15 & 55 & 0.1 & 10 & 7 & 95.88 & 96.72 \\
\hline 16 & 10 & 0.7 & 725 & 7 & 78.85 & 77.61 \\
\hline 17 & 10 & 0.4 & 725 & 2 & 79.00 & 82.00 \\
\hline 18 & 100 & 0.4 & 10 & 7 & 96.62 & 97.47 \\
\hline 19 & 100 & 0.1 & 725 & 7 & 98.58 & 97.97 \\
\hline 20 & 55 & 0.1 & 725 & 12 & 98.36 & 99.40 \\
\hline 21 & 55 & 0.7 & 10 & 7 & 87.60 & 87.82 \\
\hline 22 & 55 & 0.4 & 725 & 7 & 96.95 & 97.14 \\
\hline 23 & 10 & 0.1 & 725 & 7 & 93.05 & 91.70 \\
\hline 24 & 55 & 0.4 & 725 & 7 & 96.90 & 97.14 \\
\hline 25 & 55 & 0.7 & 1440 & 7 & 91.07 & 91.97 \\
\hline 26 & 55 & 0.1 & 725 & 2 & 98.32 & 96.89 \\
\hline 27 & 10 & 0.4 & 1440 & 7 & 89.58 & 88.84 \\
\hline 28 & 100 & 0.4 & 725 & 2 & 98.05 & 99.42 \\
\hline 29 & 55 & 0.4 & 725 & 7 & 96.85 & 97.14 \\
\hline
\end{tabular}

\section{RESULTS AND DISCUSSION}

\section{Characterization of Adsorbents}

Surface area determination and elemental analysis The surface area characteristics of DSAC and DPAC were discovered using Brunauer, Emmett and
Teller (BET) analysis, and their results are depicted in Table 3. The values of the BET surface area for both adsorbents are considerably high, which suggests that DSAC and DPAC possess surface properties that are suitable as adsorbent materials for the uptake of RhB. The result obtained also 
showed that the surface area and pore volume of DSAC is higher than that of DPAC with both adsorbents having pore diameter considered to be mesoporous (in the range of $2-50 \mathrm{~nm}$ ) (22). It is expected that both adsorbents would be good materials in the sorption of dye. The EDX analysis showed a higher percentage of carbon and a lower oxygen percentage (see Table 3 ) for both DSAC and DPAC which is a result of the acid treatment.

Table 3: Characteristics of DSAC and DPAC.

\begin{tabular}{|c|c|c|}
\hline Adsorbents & DSAC & DPAC \\
\hline BET Surface area $\left(\mathrm{m}^{2} \mathrm{~g}^{-1}\right)$ & 305.00 & 301.77 \\
\hline $\begin{array}{l}\text { Average pore volume } \\
\left(\mathrm{cm}^{3} \mathrm{~g}^{-1}\right)\end{array}$. & 0.18 & 0.16 \\
\hline $\begin{array}{l}\text { Average } \\
(\mathrm{nm})\end{array}$ & 3.48 & 4.04 \\
\hline$\% \mathrm{C}$ & 74.08 & 79.36 \\
\hline$\% 0$ & 25.79 & 20.46 \\
\hline
\end{tabular}

FTIR spectroscopic analysis of DSAC and DPAC

FTIR spectroscopy was used to monitor the adsorption of RhB onto DSAC and DPAC. Figures $1 \mathrm{a}$ and $1 \mathrm{~b}$ show the FTIR spectra of both adsorbent materials before and after adsorption. DSAC spectra before adsorption show a strong absorption peak at $3436.39 \mathrm{~cm}^{-1}$ due to $\mathrm{O}-\mathrm{H}$ stretching of alcohol $(10,23), 1573.00 \mathrm{~cm}^{-1}$ corresponding to $\mathrm{C}=\mathrm{C}$ of aromatic (23-25), $1376.56 \mathrm{~cm}^{-1}$ attributed to $\mathrm{C}-\mathrm{O}$ stretching vibration (24). After adsorption, there was a decrease in intensity and shift in adsorption bands to $\mathrm{O}-\mathrm{H}$
(3430.27 $\left.\mathrm{cm}^{-1}\right)$ and $\mathrm{C}=\mathrm{C}\left(1566.88 \mathrm{~cm}^{-1}\right)$. In addition, there was a disappearance of C-O stretching vibration, which indicates that the functional group partakes in the adsorption process (11). For DPAC, there were reductions in the intensities and shift of bands from 3433.92$3415.87 \mathrm{~cm}^{-1}$ (O-H of alcohol), 1603.56-1588.46 $\mathrm{cm}^{-1}$ (C=C of aromatic), $1701.62-1693.10 \mathrm{~cm}^{-1}$ $(\mathrm{C}=\mathrm{O})(23,26,27)$ and $1231.74-1221.39 \mathrm{~cm}^{-1}(\mathrm{C}-\mathrm{O}$ stretching). However a new peak appeared at $753.76 \mathrm{~cm}^{-1}$ (aromatic vibrations), revealing the uptake of RhB by DPAC (11).

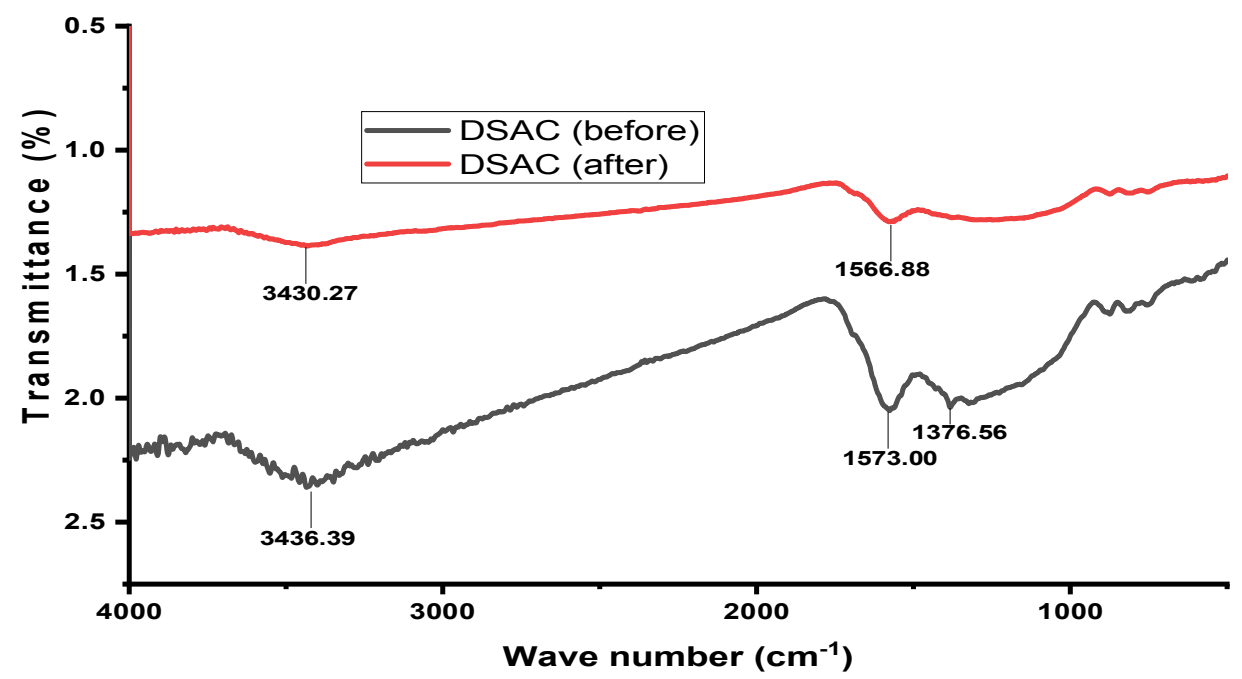

Figure 1a: FTIR spectra of DSAC (before and after adsorption). 


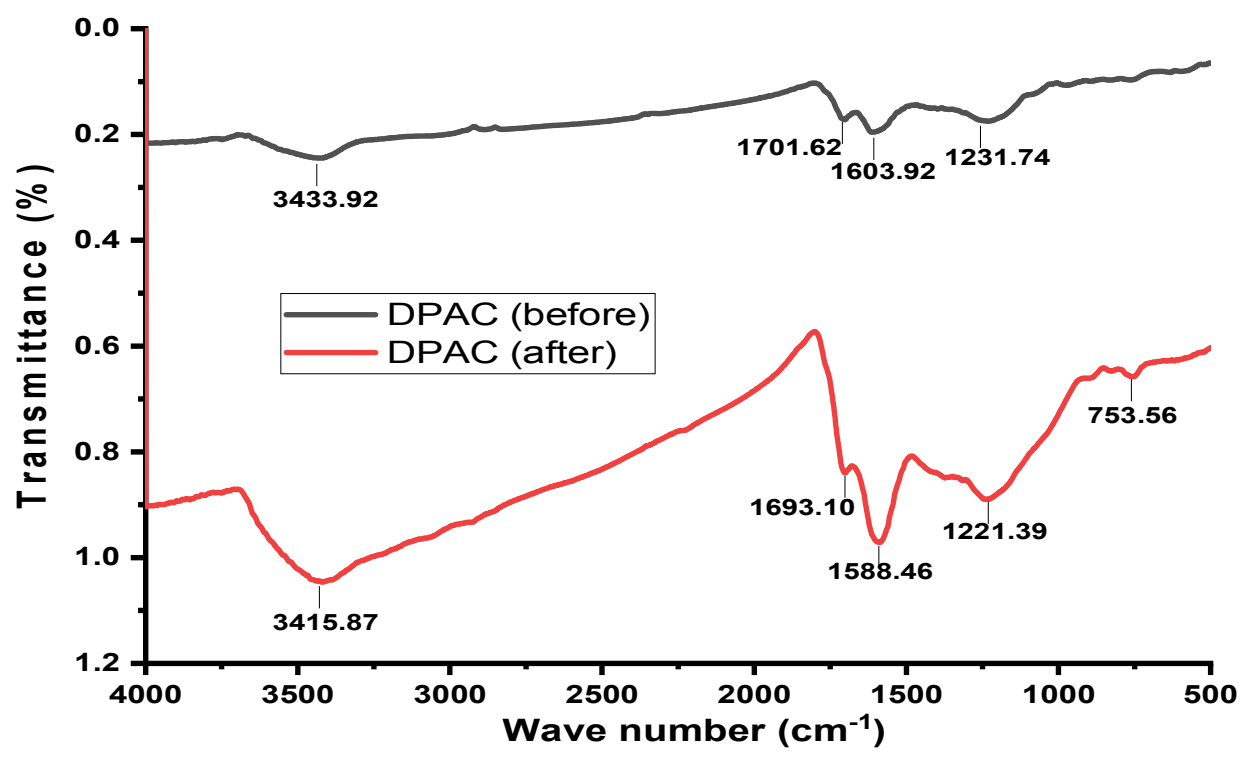

Figure 1b: FTIR spectra of DPAC (before and after adsorption).

\section{Scanning electron microscopy (SEM)}

SEM analysis was conducted to examine the surface morphologies of DSAC and DPAC before and after adsorption of RhB as shown in Figure 2. The SEM micrograph of DSAC before adsorption (Figure 2a) showed that there are many pores

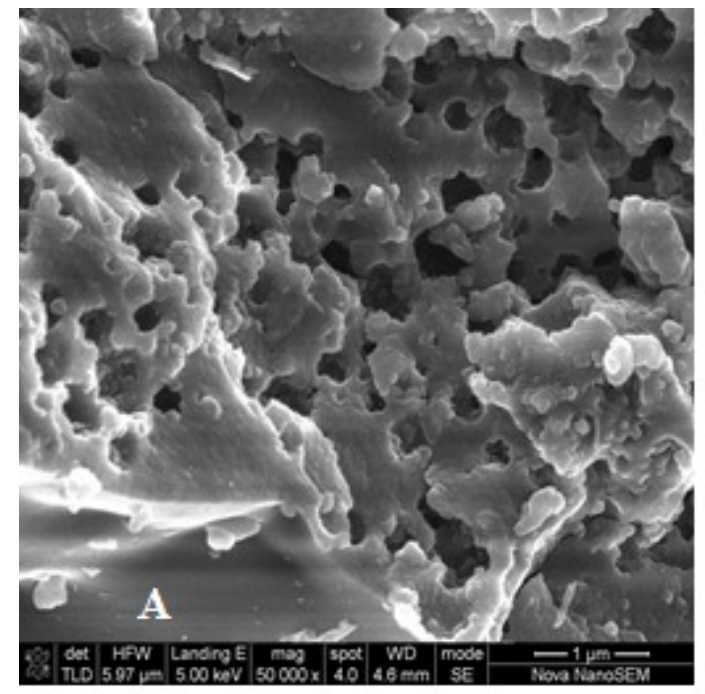

available for adsorption of RhB compared to DPAC (Figure 2c) with uneven like stone rough surfaces due to activation by acid treatment $(10,28)$. The SEM micrographs of the loaded DSAC and DPAC (Figure $2 b \& 2 d$ ) indicated that the surfaces have been covered by RhB dye molecules.

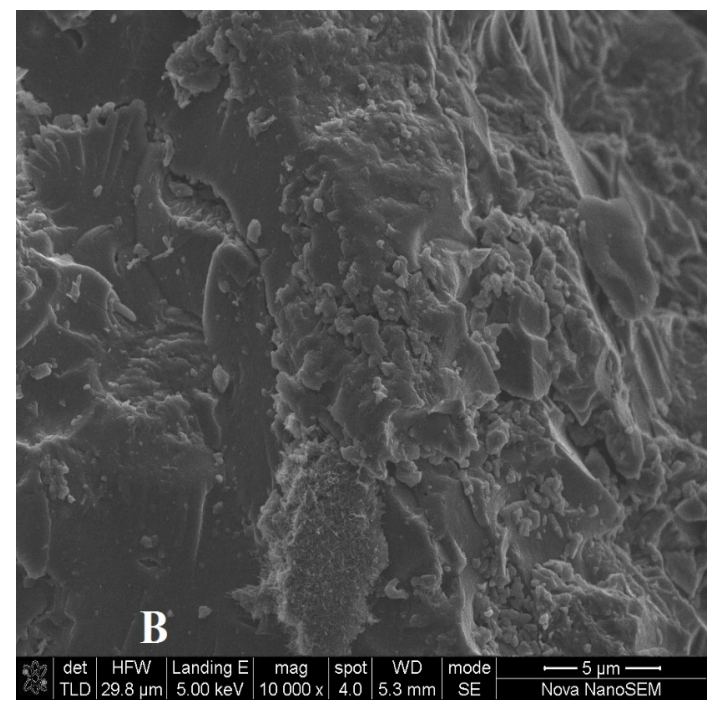



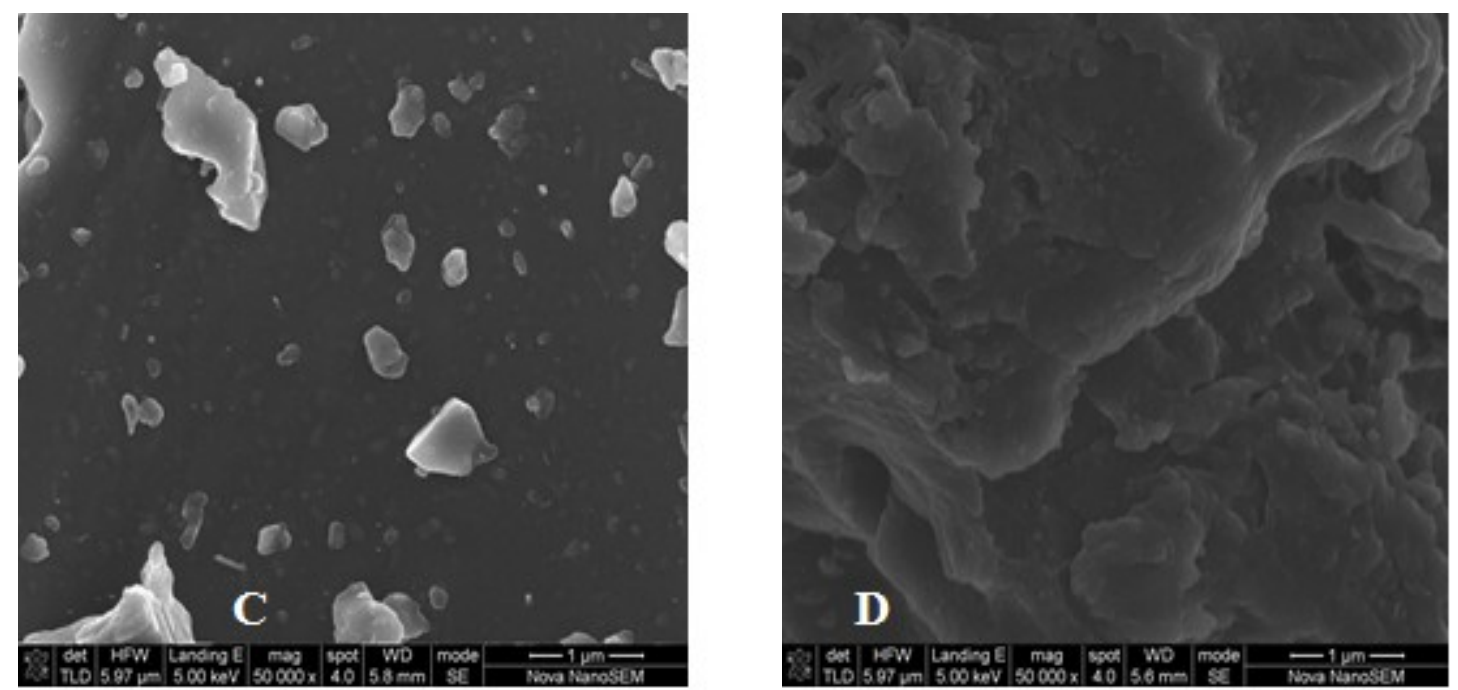

Figure 2: SEM micrograph of the adsorbents: (a) DSAC before RhB adsorption, (b) DSAC after RhB adsorption; (c) DPAC before RhB adsorption, and (d) DPAC after RhB adsorption.

Formulation of Model and optimization of adsorption of RhB onto DSAC and DPAC by BBD

BBD as a modeling technique was employed to analyze the relationship between the experimental variables to the sorption of RhB onto DSAC and DPAC and their corresponding responses of RhB removal efficiency from aqueous solution as presented in Table 1 and 2 . The removal efficiency of RhB by DSAC and DPAC was found to be greater than $99 \%$ and $98 \%$ respectively. The quadratic model equation between the adsorption responses depict RhB removal efficiency $(H)$ and the operating variables; initial concentrations $(A)$, adsorbent dosage $(B)$, time $(C)$, and $\mathrm{pH}$ (D) achieved by Design expert 11.1 .2 .0 is given in Equations (3) and (4).

$$
\begin{gathered}
H_{D S A C}=+98.05+5.72 A-3.49 B+2.14 C+1.12 D+1.80 A B+0.1125 A C-0.1450 A D+0.7850 B C \\
+0.2675 B D-1.74 C-5.97 A^{2}-0.8794 B^{2}-2.59 C^{2}+0.1843 D^{2} \\
\text { (Eq. 3) } \\
H_{D P A C}=+97.14+6.06 A-4.12 B+1.74 C+0.9317 D+2.93 A B-1.53 A C-2.65 A D+0.3325 B C \\
-0.3250 B D-0.8650 C D-4.407 A^{2}-2.02 B^{2}-1.11 C^{2}+1.10 D^{2} \\
\text { (Eq. 4) }
\end{gathered}
$$

$\mathrm{H}_{\text {DSAC }}$ and $\mathrm{H}_{\text {DPAC }}$ are the removal efficiency (response variables) and A, B, C, and D are the coded operating variables. To establish the regression model, which is significant statistically,

$$
\begin{gathered}
H_{D S A C}=+98.05+5.72 A-3.49 B+2.14 C+1.12 D+1.80 A B-1.74 C D-5.97 A^{2}-2.59 C^{2} \text { (Eq. 5) } \\
H_{D P A C}=+97.14+6.06 A-4.12 B+1.74 C+0.9317 D+2.93 A B-2.65 A D+0.3325 B C \text { (Eq. 6) } \\
-4.407 A^{2}-2.02 B^{2}
\end{gathered}
$$

the insignificant terms in Equations 3 and 4 with $p$ values >0.05 were removed. Consequently, Eequations 5 and 6 were obtained;
The suitability of the proposed models was evaluated by the Design expert 11.1.2.0 as shown in Tables 4 and 5. The $F$-values 24.82 and 27.86 for DSAC and DPAC respectively of the quadratic model and their low $p$ values $(<0.0001)$ suggested that the models are significant. The regression coefficient $\left(R^{2}\right)$ values 0.9613 and 0.9653 were high. The adjusted $\left(R^{2}\right)$ values of 0.9225 (DSAC) and 0.9307 (DPAC) compared with the predicted $R^{2}(0.7791)$ and 0.8040 for both adsorbents were in reasonable agreement. A model is considered significant if its $p$-value $<0.05$. As presented in Tables 4 and 5 , it can be seen that the linear terms $A, B, C, D$, the interaction terms $A B$ and $C D$, and the quadratic terms $A^{2}$ and $C^{2}$ are the significant terms for RhB onto DSAC. While linear terms ( $A, B$, and $C)$, interaction terms ( $A B$ and $A D)$, and the quadratic terms $\left(A^{2}\right.$ and $\left.B^{2}\right)$ are significant for $R h B$ onto DPAC $(17,29)$. 
Table 4: Anova for quadratic model on the removal RhB onto DSAC.

\begin{tabular}{|c|c|c|c|c|c|c|}
\hline Source & $\begin{array}{l}\text { Sum of } \\
\text { Squares }\end{array}$ & df & $\begin{array}{l}\text { Mean } \\
\text { Square }\end{array}$ & F-value & p-value & Comments \\
\hline Model & 900.19 & 14 & 64.30 & 24.82 & $<0.0001$ & Significant \\
\hline A-Concentration & 393.31 & 1 & 393.31 & 151.82 & $<0.0001$ & Significant \\
\hline B-Dose & 146.16 & 1 & 146.16 & 56.42 & $<0.0001$ & Significant \\
\hline C-Time & 54.91 & 1 & 54.91 & 21.20 & 0.0004 & Significant \\
\hline D-pH & 15.12 & 1 & 15.12 & 5.84 & 0.0299 & Significant \\
\hline$A B$ & 12.92 & 1 & 12.92 & 4.99 & 0.0423 & Significant \\
\hline$A C$ & 0.0506 & 1 & 0.0506 & 0.0195 & 0.8908 & \\
\hline$A D$ & 0.0841 & 1 & 0.0841 & 0.0325 & 0.8596 & \\
\hline BC & 2.46 & 1 & 2.46 & 0.9515 & 0.3459 & \\
\hline$B D$ & 0.2862 & 1 & 0.2862 & 0.1105 & 0.7445 & \\
\hline$C D$ & 12.11 & 1 & 12.11 & 4.67 & 0.0484 & Significant \\
\hline$A^{2}$ & 231.33 & 1 & 231.33 & 89.30 & $<0.0001$ & Significant \\
\hline$B^{2}$ & 5.02 & 1 & 5.02 & 1.94 & 0.1858 & \\
\hline$C^{2}$ & 43.62 & 1 & 43.62 & 16.84 & 0.0011 & Significant \\
\hline$D^{2}$ & 0.2204 & 1 & 0.2204 & 0.0851 & 0.7748 & \\
\hline Residual & 36.27 & 14 & 2.59 & & & \\
\hline Pure Error & 0.4873 & 4 & 0.1218 & & & \\
\hline Cor Total & 936.46 & 28 & & & & \\
\hline Cor Total & 936.46 & 28 & & & & \\
\hline Std. Dev. & 1.61 & & & & & \\
\hline
\end{tabular}

Mean = 94.22; C.V.\% $\% 1.71 ; \mathrm{R}^{2}=0.9613 ;$ Adjusted. $R^{2}=0.9225 ;$ Predicted. $R^{2}=0.7791 ;$ Adeq . Precision $=18.5854$

Table 5: Anova for quadratic model on the removal of RhB onto DPAC.

\begin{tabular}{|c|c|c|c|c|c|c|}
\hline Source & $\begin{array}{l}\text { Sum of } \\
\text { Squares }\end{array}$ & df & $\begin{array}{c}\text { Mean } \\
\text { Square }\end{array}$ & F-value & p-value & Comments \\
\hline Model & 902.04 & 14 & 64.43 & 27.86 & $<0.0001$ & Significant \\
\hline A-Concentration & 440.93 & 1 & 440.93 & 190.65 & $<0.0001$ & Significant \\
\hline B-Dose & 203.45 & 1 & 203.45 & 87.97 & $<0.0001$ & Significant \\
\hline C-Time & 36.44 & 1 & 36.44 & 15.75 & 0.0014 & Significant \\
\hline $\mathrm{D}-\mathrm{pH}$ & 10.42 & 1 & 10.42 & 4.50 & 0.0521 & \\
\hline$A B$ & 34.22 & 1 & 34.22 & 14.80 & 0.0018 & Significant \\
\hline$A C$ & 9.30 & 1 & 9.30 & 4.02 & 0.0646 & \\
\hline$A D$ & 28.09 & 1 & 28.09 & 12.15 & 0.0036 & Significant \\
\hline $\mathrm{BC}$ & 0.4422 & 1 & 0.4422 & 0.1912 & 0.6686 & \\
\hline $\mathrm{BD}$ & 0.4225 & 1 & 0.4225 & 0.1827 & 0.6756 & \\
\hline$C D$ & 2.99 & 1 & 2.99 & 1.29 & 0.2744 & \\
\hline$A^{2}$ & 125.75 & 1 & 125.75 & 54.38 & $<0.0001$ & Significant \\
\hline $\mathrm{B}^{2}$ & 26.52 & 1 & 26.52 & 11.47 & 0.0044 & Significant \\
\hline$C^{2}$ & 7.98 & 1 & 7.98 & 3.45 & 0.0843 & \\
\hline$D^{2}$ & 7.79 & 1 & 7.79 & 3.37 & 0.0879 & \\
\hline Residual & 32.38 & 14 & 2.31 & & & \\
\hline Pure Error & 0.8055 & 4 & 0.2014 & & & \\
\hline Cor Total & 934.41 & 28 & & & & \\
\hline Std. Dev. & 1.52 & & & & & \\
\hline
\end{tabular}

Mean = 93.57; C.V. $\%=1.63 ; \mathrm{R}^{2}=0.9653 ;$ Adjusted. $R^{2}=0.9307 ;$ Predicted. $R^{2}=0.8040 ;$ Adeq. Precision $=20.0466$

Figure 3 ( $a$ and $b$ ) are the actual versus predicted plots for both adsorbents. It is apparent that the data points on the plots were distributed close to the straight line; thus, implying a good relationship between the actual and predicted values of the responses. This is following the report of $(17,29)$. These results clearly showed that the quadratic model tested was sufficient in predicting the response variables for the experimental data. 

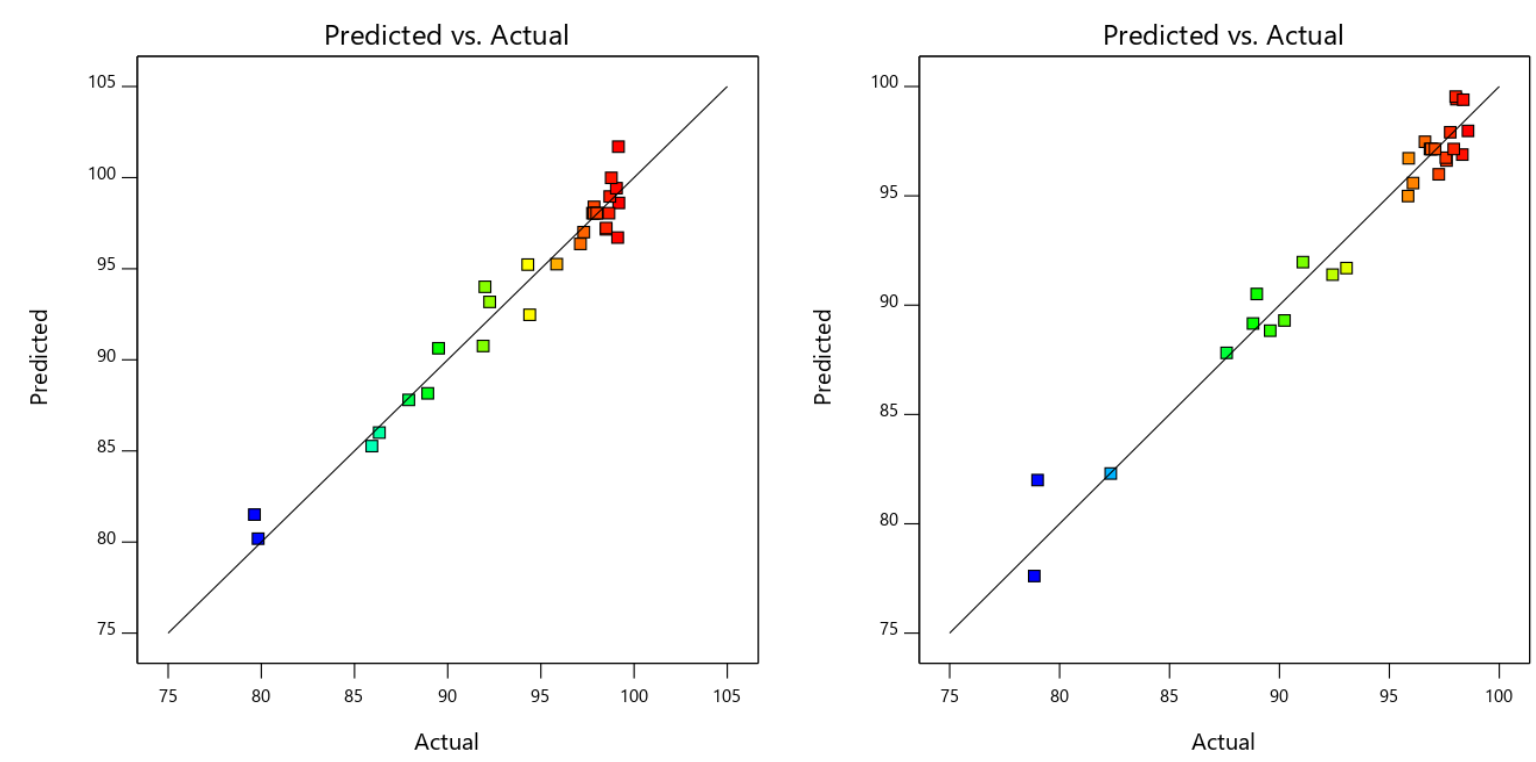

Figure 3: Actual vs predicted plots of RhB on DSAC (left), DPAC (right).

The 3-D response surface plots (Figures 4-9) were developed to determine the effect of the combinations of operating variables on the removal efficiency of RhB onto DSAC and DPAC. In Figures 4 ( $a$ and $b$ ), it is apparent that the adsorption process is greatly affected by the $\mathrm{pH}$ of a solution. The charge on the adsorbent's surface and the nature of adsorbate in solution depends on $\mathrm{pH}$. The figures show the effects of $\mathrm{pH}$ and initial concentration on the sorption of RhB onto DSAC and DPAC. The percentage of RhB sorbed was noticed to increase as the $\mathrm{pH}$ and concentration increased for both adsorbents at fixed adsorbent dosage $(0.1 \mathrm{~g})$ and time (725 $\mathrm{min})$. This is because, at higher $\mathrm{pH}$, there are more hydroxyl ions in the solution resulting in electrostatic attraction between RhB dye and the adsorbents. However, at lower $\mathrm{pH}$, there are more protons in the solution and the surface of the RhB dye is cationic thereby leading to electrostatic repulsion between the adsorbents and adsorbate in solution. Hence a decrease in the removal efficiency of RhB dyes. This is in line with the observations made by $(21,26,30)$. The interaction between initial concentration and contact time is presented in Figure 5 ( $a$ and $b$ ). The percentage removal of RhB with time increases until equilibrium was attained at $60 \mathrm{mg} / \mathrm{L}$ and $725 \mathrm{~min}$ for both adsorbents. Figure 6 ( $a$ and $b$ ) depicted that there was better interaction between the adsorbent dose and concentration of RhB. The removal efficiency of RhB was low at a higher dosage and lower concentration. Although, the removal efficiency increases as the concentration increased at a lower dose. This may be attributed to the overcrowding of the adsorbent particle at the adsorption site at a higher dosage. Figure 7 ( $a$ and $b$ ) gives the reliance of removal efficiency of RhB on adsorption time and $\mathrm{pH}$ for both adsorbents. The percentage removal of $\mathrm{RhB}$ is low at a lower time and $\mathrm{pH}$ as a result of more positive ions in the solution. While at high adsorption time and $\mathrm{pH}$ the rate of sorption was higher and this is due to the electrostatic attraction between RhB dye and the adsorbents as well as more interactions between the dye molecule and the adsorbents. Figure 8 ( $a$ and $b$ ) depicts the effect of the dual interaction between dose and $\mathrm{pH}$ on the response for complete $\mathrm{RhB}$ adsorbed from aqueous solution at a fixed initial RhB concentration and contact time. This dual interaction has no significant impact $(p>0.05)$ on the adsorption of RhB for both adsorbents. The highest percentage removal of RhB was recorded at a lower dose and high $\mathrm{pH}$. At a lower dose, there are several vacant sites ready for adsorption and at higher $\mathrm{pH}$, there are more negative ions in the solution resulting in electrostatic interaction between RhB dye and the adsorbents. Thus, the enhanced removal efficiency of RhB dyes. These observations align with the reports of $(26,30)$. The interactive effect between dose and time on the response surface for the percentage removal of RhB by DSAC and DPAC at constant $\mathrm{pH}$ and initial RhB concentration is presented in Figure 9 ( $a$ and b). The adsorption efficiency of RhB was at the highest at a low dosage for both adsorbents and increases as the time of contact increases revealing an antagonistic effect between the two variables (26). 

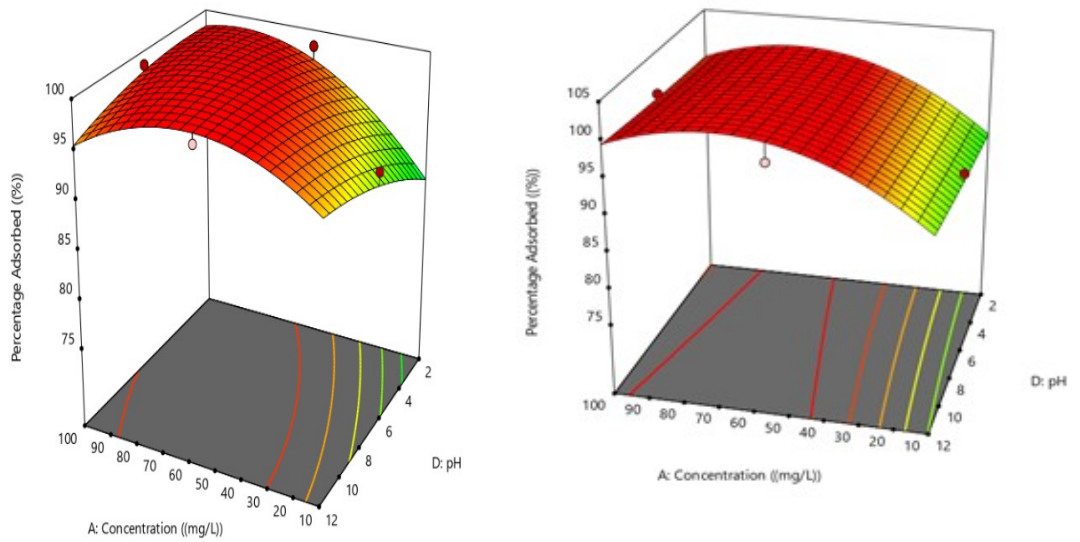

Figure 4: $3 \mathrm{D}$ plots on the effect of concentration and $\mathrm{pH}$ on adsorption of RhB on DSAC (left); DPAC (right) at $0.1 \mathrm{~g}$ dose and $725 \mathrm{~min}$.
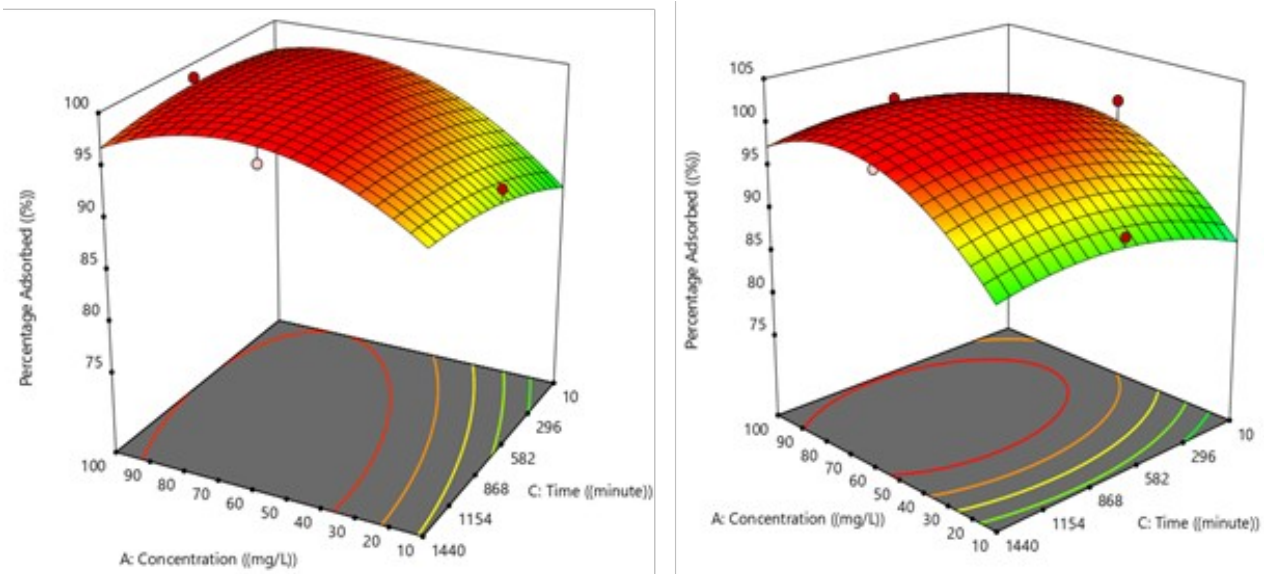

Figure 5: 3D plots on the effect of concentration and time on adsorption of RhB on DSAC (left); (b) DPAC (right) at $0.1 \mathrm{~g}$ dose and $\mathrm{pH} 12$.
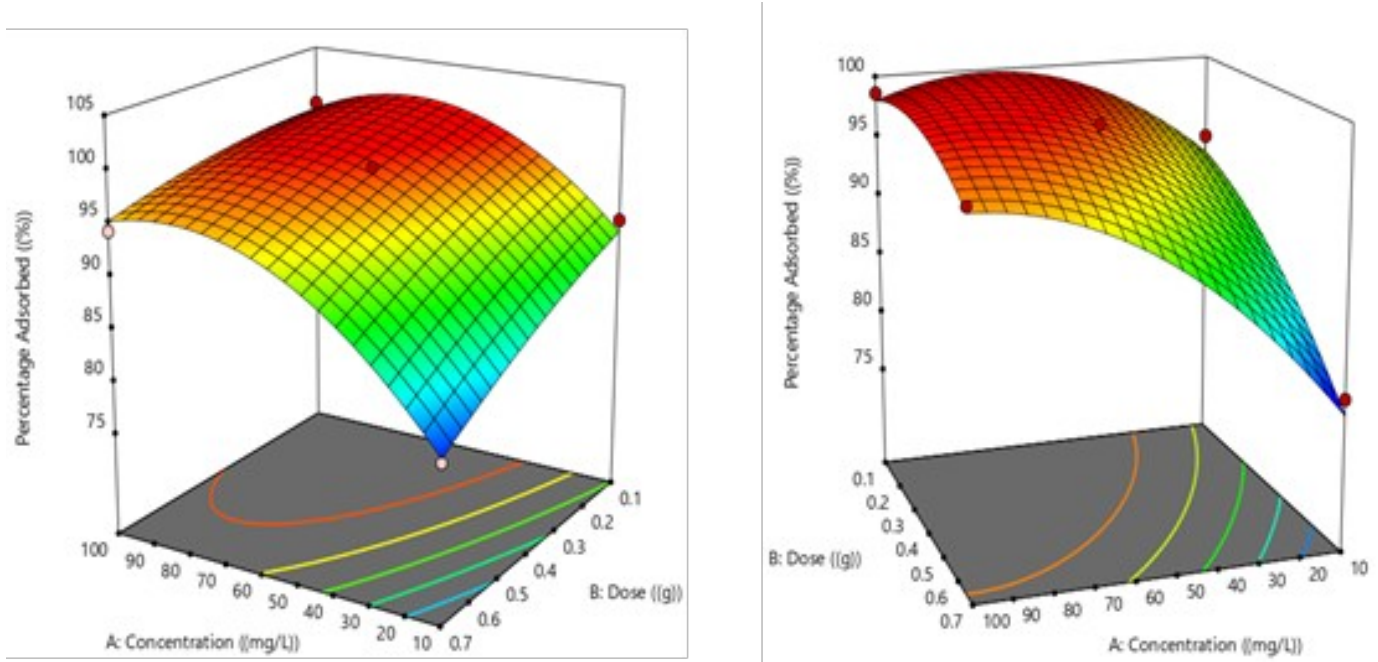

Figure 6: 3D plots on the effect of concentration and dose on adsorption of RhB on (left) DSAC; (right) DPAC at $\mathrm{pH} 12$ and $725 \mathrm{~min}$. 

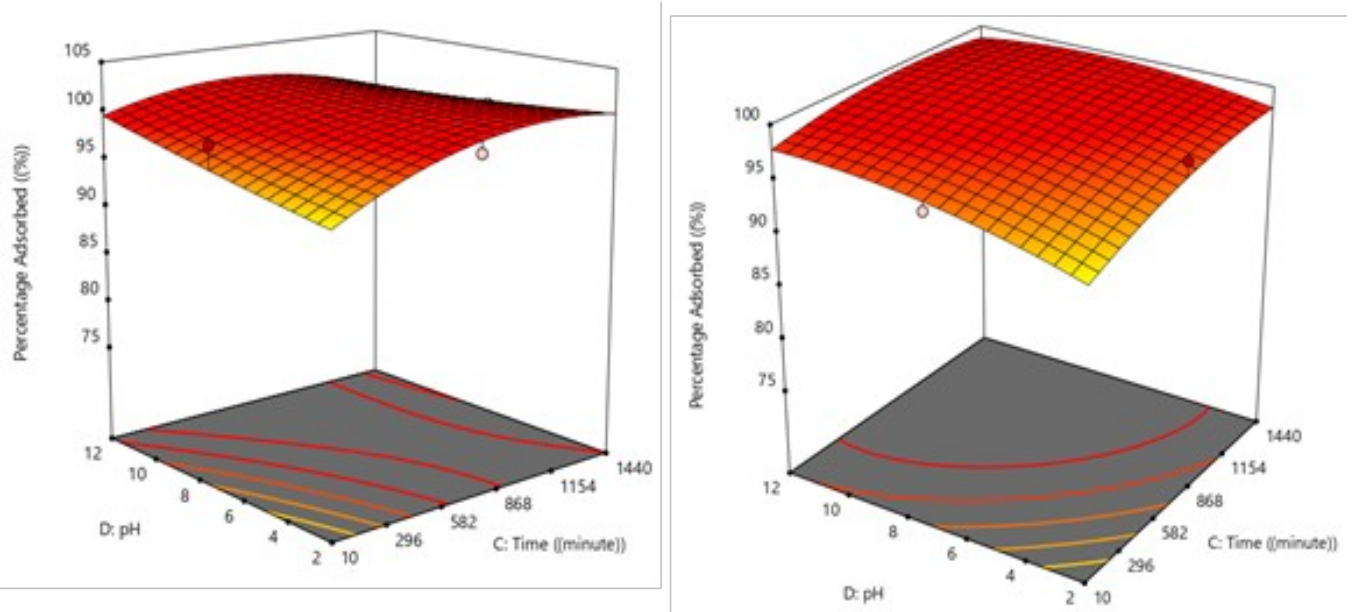

Figure 7: 3D plots on the effect of time and $\mathrm{pH}$ on adsorption of RhB on DSAC (left); DPAC (right) at 55 $\mathrm{mg} / \mathrm{L}$ and $0.1 \mathrm{~g}$.
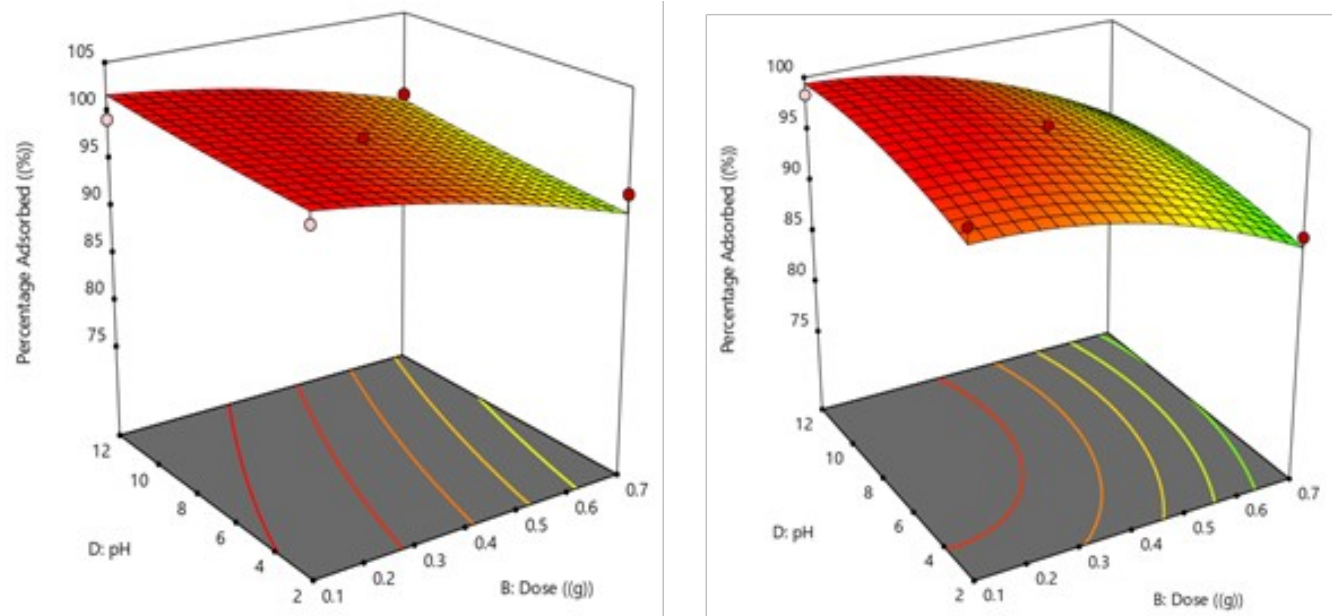

Figure 8: 3D plots on the effect of Dose and pH on adsorption of RhB on (a) DSAC; (b) DPAC at $55 \mathrm{mg} / \mathrm{L}$ and $725 \mathrm{~min}$.
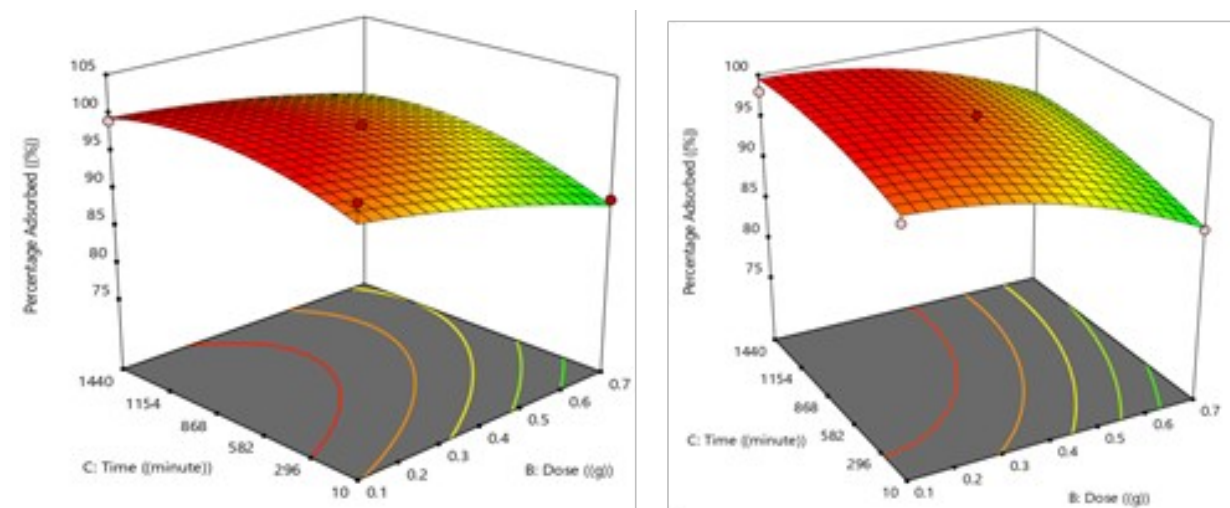

Figure 9: 3D plots on the effect of Dose and Time on adsorption of RhB on (left) DSAC; (right) DPAC at $55 \mathrm{mg} / \mathrm{L}$ and $\mathrm{pH} 12$.

Interactive effects of the parameters on RhB removal onto DSAC and DPAC

The perturbation plot is usually employed to study the interactions among all operating variables simultaneously (31). Figure 10 ( $a$ and $b$ ) shows the percentage removal of $\mathrm{RhB}$ as a function of each operating parameter from the lowest coded value with other parameters at a constant level in the center point of the design. In Figure 10, it is obvious that initial concentration, adsorbent dose, contact time, and $\mathrm{pH}$ have an observable impact on $\mathrm{RhB}$ removal for both adsorbents. 


\section{Adsorption isotherm}

Isotherms are primarily used to illustrate the adsorption process. It explains how the adsorbate relates with the adsorbent and explains the nature and mechanism of the adsorption procedure (32). The adsorption isotherm data of RhB onto DSAC and DPAC were studied by Freundlich, Langmuir, and Temkin isotherms. The nearness of the value of the correlation coefficient $\left(R^{2}\right)$ to one, the better is the agreement of the experimental data with the model. The Langmuir isotherm validates the adsorption process as a monolayer on a surface having a finite number of similar sites. A linear form of the Langmuir isotherm is expressed in Equation 7a. The dimensionless equilibrium parameter $\left(R_{L}\right)$ represented in Equation $7 \mathrm{~b}$ confirms the favorability of the process. The adsorption process is favorable if $R_{L}$ value falls between 0 and $1\left(0<R_{L}<1\right)$, linear when $R_{L}=1$, irreversible when $R_{L}=0$ and unfavorable when $R_{L}>$ 1. Where $C_{e}$ is the equilibrium concentration of the $\mathrm{RhB}$ in solution $(\mathrm{mg} / \mathrm{L}), \mathrm{q}_{e}$ is the amount of $\mathrm{RhB}$ adsorbed per unit mass of adsorbate $(\mathrm{mg} / \mathrm{g}), \mathrm{Q}_{\mathrm{o}}$, and $\mathrm{K}_{\mathrm{L}}$ is the adsorption capacity and the Langmuir equilibrium constant of adsorption, respectively. Freundlich isotherm described the heterogeneity of the adsorption process i.e. a multilayer adsorption mechanism as presented in Equation 8. $K_{f}$ and $n$ are the Freundlich constants calculated from the slopes and intercepts of the linear graphs of $\log q_{e}$ versus $\log C_{e} . C_{e}$ is the equilibrium concentration of the RhB in solution (mg/L). qe the amount of RhB adsorbed per unit mass of adsorbate $(\mathrm{mg} / \mathrm{g}), \mathrm{n}$ indicates how favorable is the adsorption process and $\mathrm{K}_{\mathrm{f}}$ reflects the adsorption strength. The Temkin model believes that heat of adsorption decreases linearly with coverage as represented in Equation 9. It considers the adsorbent-adsorbate relationship. $A_{T}$ is the Temkin equilibrium constant $(\mathrm{L} / \mathrm{g}), \mathrm{b}_{\mathrm{T}}$ is the Temkin constant related to the heat of sorption $(\mathrm{J} / \mathrm{mol})$ which can be calculated from the plot of $\mathrm{q}_{\mathrm{e}}$ against $\ln \mathrm{C}_{\mathrm{e}} . \mathrm{R}$ is the molar gas constant $(8.314 \mathrm{~J} / \mathrm{mol} / \mathrm{K})$, and $\mathrm{T}$ is the absolute temperature $(10,26)$.

$$
\begin{gathered}
\frac{C_{e}}{q_{e}}=\frac{1}{Q_{0} K_{L}}+\frac{1}{Q_{0}} C_{e} \text { (Eq. 7a) } \\
R_{L}=\frac{1}{\left(1+K_{L} C_{o}\right)} \quad \text { (Eq. 7b) } \\
\log q_{e}=\frac{1}{n} \log C_{e}+\log K_{f} \text { (Eq. } \\
q_{e}=\frac{R T}{b_{T}} \ln A_{T}+\frac{R T}{b_{T}} \ln C_{e} \text { (Eq. }
\end{gathered}
$$
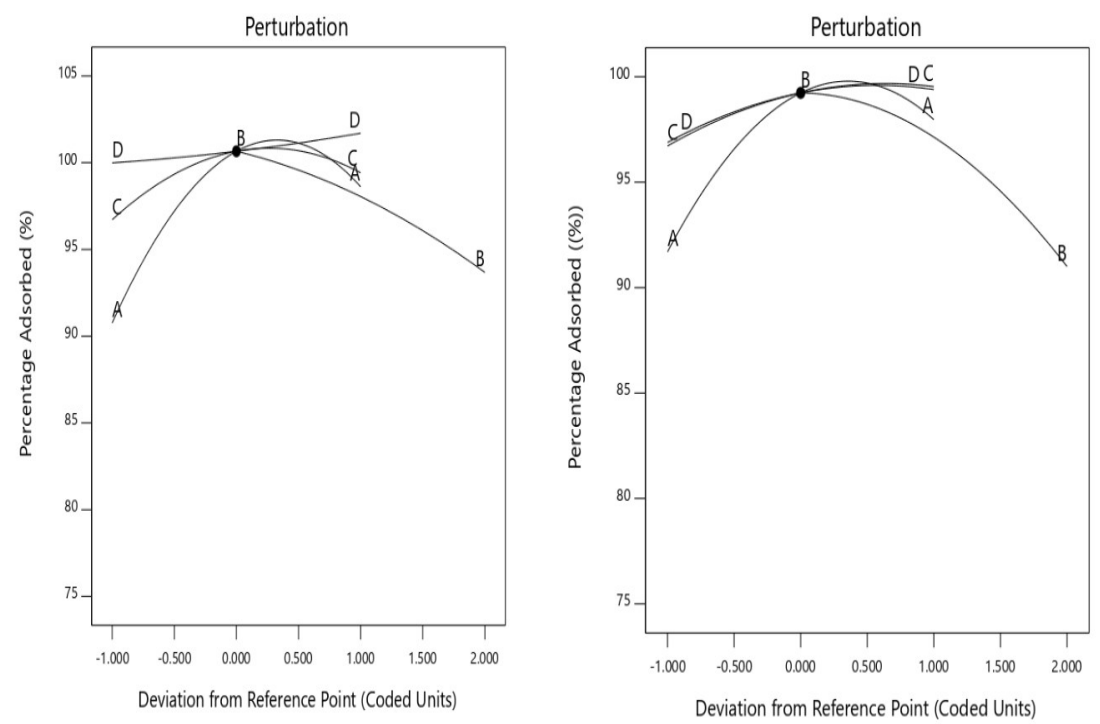

Figure 10: Perturbation plots for the percentage of RhB removal onto DSAC (left); DPAC (right). 


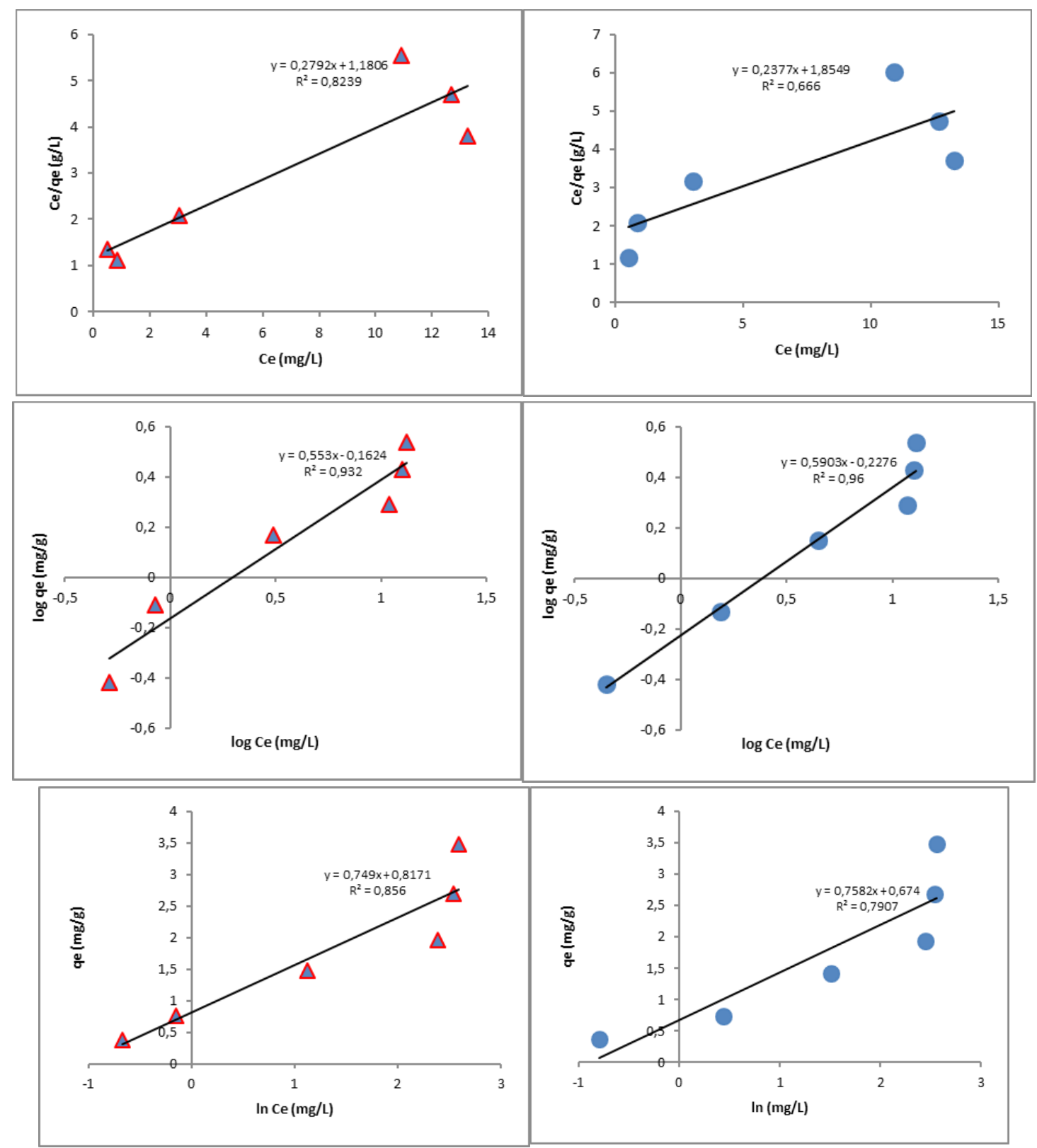

Figure 11: (Top row) Langmuir Isotherm plots for the sorption of RhB onto DSAC and DPAC; (middle row) Freundlich Isotherm plots for the sorption of RhB onto DSAC and DPAC; (bottom row) Temkin Isotherm plots for the sorption of RhB onto DSAC and DPAC.

The results of the isotherm studies and their related parameters obtained are shown in Figure 11 and Table 6 . The correlation coefficient values $\left(R^{2}\right)$ of Freundlich isotherm (0.932 and 0.960$)$ for RhB onto DSAC and DPAC respectively were found to be higher compared to that of the Langmuir model (0.825 and 0.740) and Temkin isotherm (0.857 and 0.791) which implies that the adsorption process fitted best into Freundlich isotherm model. This means that the sorption of RhB onto the surfaces of DSAC and DPAC was heterogeneous. The values of $n$ calculated for both adsorbents were greater than one indicating the favorability of the adsorption process while the constant $K_{f}$ with values of 0.689 and $0.593(\mathrm{mg} / \mathrm{g})$ for both DSAC and DPAC respectively, revealed that there was greater adsorption affinity between $\mathrm{RhB}$ and DSAC than DPAC. This is in concordance with the observation of (11). However, the process could not be described by both Langmuir and Temkin isotherm due to low $R^{2}$ values $\left(R^{2}<0.9\right)$. Their constants are presented in Table 6. 
Table 6: Isotherm parameters for the uptake of RhB onto DSAC and DPAC.

\begin{tabular}{llll}
\hline $\begin{array}{l}\text { Isotherm } \\
\text { model }\end{array}$ & Parameters/constants & DSAC & DPAC \\
\hline Freundlich & $\mathrm{R}^{2}$ & 0.932 & 0.960 \\
& $\mathrm{~K}_{\mathrm{f}}$ & 0.689 & 0.593 \\
Langmuir & $\mathrm{n}^{2}$ & 1.808 & 1.695 \\
& $\mathrm{R}^{2}(\mathrm{mg} / \mathrm{g})$ & 0.825 & 0.740 \\
& $\mathrm{q}_{\mathrm{o}}(\mathrm{l})$ & 3.584 & 4.219 \\
& $\mathrm{~K}_{\mathrm{L}}(\mathrm{L} / \mathrm{mg})$ & 0.236 & 0.128 \\
Temkin & $\mathrm{R}_{\mathrm{L}}$ & 0.078 & 0.135 \\
& $\mathrm{R}^{2}$ & 0.857 & 0.791 \\
& $\mathrm{~A}_{T}(\mathrm{~L} / \mathrm{g})$ & 2.115 & 2.134 \\
& $\mathrm{~B}_{T}(\mathrm{~J} / \mathrm{mol})$ & 3341.13 & 3301.47 \\
\hline
\end{tabular}

\section{Kinetic models}

Four kinetic models viz pseudo-first-order, pseudosecond-order, Elovich, and Intraparticle diffusion were considered for the sorption of RhB onto DSAC and DPAC to establish the kinetics and mechanism of the adsorption process.

The Pseudo-first-order rate equation as given by $(33,34)$, expressed as:

$$
\ln \left(q_{e}-q_{t}\right)=\ln q_{e, c a l}-k_{1} t \text { (Eq. 10) }
$$

The pseudo-second-order kinetic model equation was given as:

$$
\frac{t}{q_{t}}=\frac{1}{k_{2} q_{e, c a l}^{2}}+\frac{1}{q_{e, c a l}} \times t
$$

The Elovich equation is expressed as:

$$
q_{t}=\frac{1}{\alpha} \ln (\alpha \beta)+\frac{1}{\alpha} \ln t
$$

The intra-particle diffusion equation is expressed as:

$$
q_{t}=k_{d} t^{1 / 2}+C \text { (Eq. 13) }
$$

where $\mathrm{q}_{\mathrm{e}}$ and $\mathrm{q}_{\mathrm{t}}$ both in $\mathrm{mg} / \mathrm{g}$ are the amounts of RhB dye sorbed at equilibrium and at any time $t$ (min). $k_{1}\left(\min ^{-1}\right), k_{2}(\mathrm{~g} / \mathrm{mg} \min )$, and $\mathrm{k}_{\mathrm{d}}(\mathrm{mg} / \mathrm{g}$ $\min ^{1 / 2}$ ) are the rate constants of the pseudo-firstorder, pseudo-second-order, and intra-particle diffusion models respectively. $a$ is the initial adsorption rate $(\mathrm{mg} / \mathrm{g} \mathrm{min}$ ) and $\beta$ is the desorption constant $(\mathrm{g} / \mathrm{mg})$ while $C$ is a constant which gives an idea about the thickness of the boundary layer $(11,35)$.
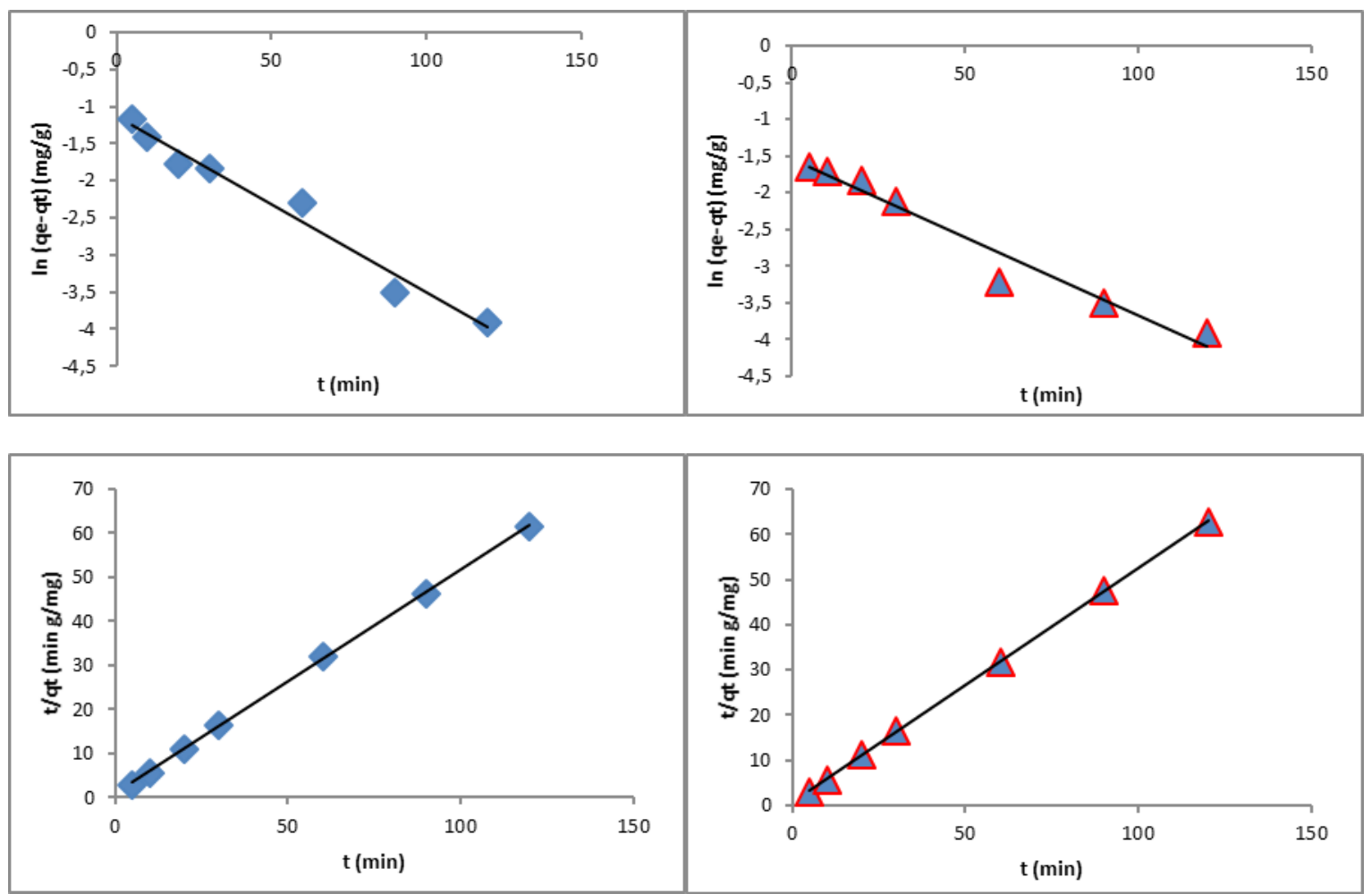


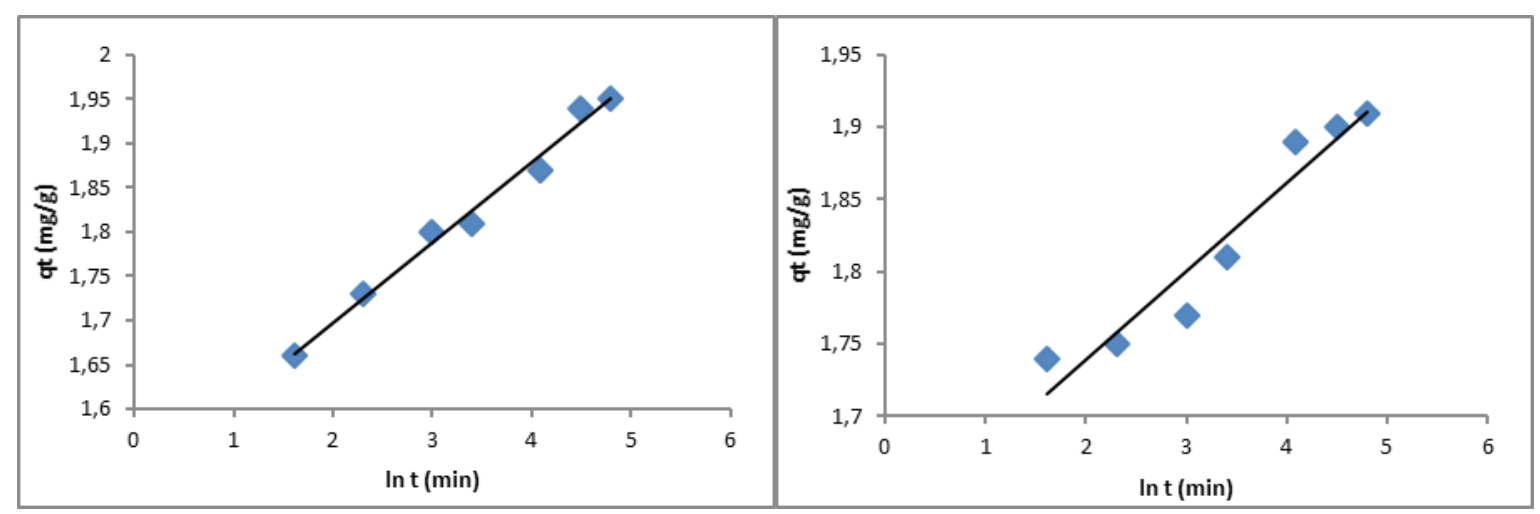

Figure 12: (Top row) Pseudo-first-order kinetics plots for the sorption of RhB onto DSAC and DPAC; (middle row) Pseudo second order kinetics plots for the sorption of RhB onto DSAC and DPAC; (bottom row) Elovic plots for the sorption of RhB onto DSAC and DPAC.

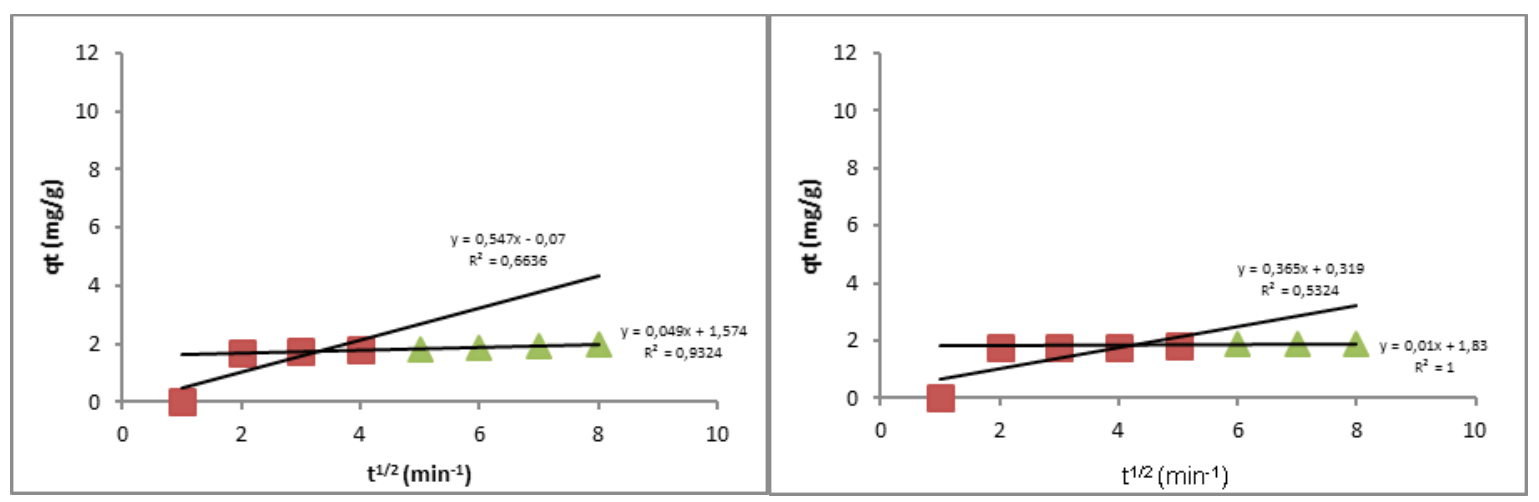

Figure 13: Intra-particle diffusion plots for the sorption of RhB onto (left) DSAC and (right) DPAC.

The graphs of all the kinetic models were presented in Figure 12 and their parameters were calculated as shown in Table 7. The plots of qt versus $t$ (Fig. $12 \mathrm{c}$ and $12 \mathrm{~d}$ ) have the highest correlation coefficient values $\left(R^{2}=0.999\right)$ for both adsorbents compared to other kinetic model plots. The calculated $\mathrm{q}_{\mathrm{e}}$ values of the pseudo-secondorder kinetic model with the experimental $\mathrm{q}_{\mathrm{e}}$ values for both DSAC and DPAC were in close agreement (Table 7). The values of the pseudosecond-order rate constants $\left(k_{2}\right) 0.282$ and 0.414 g mg-1 $\mathrm{min}^{-1}$ for DSAC and DPAC respectively indicated that the adsorption is fast. Impliedly, the adsorption followed the pseudo-second-order kinetics model which adequately described the process. Indicating that the chemical process appeared to control the adsorption of RhB onto
DSAC and DPAC. This conforms to the results of $(11,29)$.

The intra-particle diffusion plots of RhB onto DSAC and DPAC were given in Figure 13 and their constant parameters were calculated (Table 8). The figures revealed that the adsorption process is in two stages. The first segment is the exterior surface adsorption of RhB while the second linear part is the progressive adsorption of the RhB stage where intra-particle or pore diffusion was ratelimiting. The higher correlation coefficient $\left(R^{2}\right)$ values and high boundary layer $(C)$ of the second stage is an indication that intra-particle diffusion appears to control the adsorption of RhB onto both adsorbents but is not the only rate-limiting step. These observations follow the reports of $(26,29)$. 
Table 7: Kinetic parameters for the sorption of RhB onto DSAC and DPAC.

\begin{tabular}{llll}
\hline Kinetic models & Parameters & DSAC & DPAC \\
\hline Pseudo first order & $\mathrm{K}_{1}\left(\mathrm{~min}^{-1}\right)$ & 0.023 & 0.021 \\
& $\mathrm{Q}_{\mathrm{e}, \mathrm{cal}}(\mathrm{mg} / \mathrm{g})$ & 0.32 & 0.21 \\
& $\mathrm{R}^{2}$ & 0.975 & 0.958 \\
Pseudo second & $\mathrm{K}_{2}(\mathrm{~g} / \mathrm{mg} / \mathrm{min})$ & 0.282 & 0.414 \\
order & $\mathrm{Q}_{e}$ cal $(\mathrm{mg} / \mathrm{g})$ & 1.97 & 1.93 \\
& $\mathrm{Q}_{e}$ exp $(\mathrm{mg} / \mathrm{g})$ & 1.96 & 1.92 \\
Elovich & $\mathrm{R}^{2}$ & 0.999 & 0.999 \\
& $\mathrm{a}$ & 11.11 & 16.39 \\
& $\beta$ & $1.85 \times 10^{6}$ & $1.95 \times 10^{10}$ \\
& $\mathrm{R}^{2}$ & 0.986 & 0.927 \\
\hline
\end{tabular}

Table 8: Intra-particle diffusion parameters for the sorption of RhB onto DSAC and DPAC.

\begin{tabular}{lllll}
\hline Parameters & \multicolumn{2}{c}{ DSAC } & \multicolumn{2}{c}{ DPAC } \\
\hline & Line 1 & Line 2 & Line 1 & Line 2 \\
\cline { 2 - 5 } $\mathrm{K}_{\mathrm{d}}\left(\mathrm{mg} / \mathrm{g} \mathrm{min}^{1 / 2}\right)$ & 0.547 & 0.049 & 0.356 & 0.01 \\
$\mathrm{C}$ & -0.07 & 1.574 & 0.319 & 1.83 \\
$\mathrm{R}^{2}$ & 0.663 & 0.932 & 0.532 & 1 \\
\hline
\end{tabular}

\section{CONCLUSION}

Based on this study and the results obtained, it can be established that both DSAC and DPAC are promising and potential materials for removing organic hazardous pollutants such as dyes from aqueous media. Adsorption operating variables such as initial RhB concentration, adsorbent dosage, time, and $\mathrm{pH}$ were successfully optimized and significant for the removal of RhB by DSAC and DPAC. The actual and predicted values having a good agreement confirms the suitability of the proposed model. The optimum removal efficiency of RhB by DSAC and DPAC occurs at $55 \mathrm{mg} / \mathrm{L}$ initial RhB concentration, $0.1 \mathrm{~g}$ dosage, $725 \mathrm{~min}$, and $\mathrm{pH}$ 12 with removal percentage greater than $99 \%$ and $98 \%$ for DSAC and DPAC respectively. Freundlich Isotherm models adequately described the adsorption process. Comparatively, DSAC appears to exhibit a better performance for the uptake of RhB than DPAC. The adsorption followed the pseudo-second-order kinetics model and adequately described the process among the kinetic models tested. Thus, the adsorption appears to be controlled by the chemical process.

\section{ACKNOWLEDGMENTS}

The authors are most grateful to Chemistry and Industrial Chemistry Unit, Kwara State University, Malete, Nigeria for providing the laboratory facilities necessary to carry out the proposed study.

\section{AUTHORS' CONTRIBUTIONS}

The authors SO Azeez, IO Saheed, FA Adekola, AA Jimoh, DM Aransiola, and ZA Abdulsalam designed and performed the experiment and as well analyzed experimental data. All the authors worked on characterization analysis and the drafting of the manuscript. All authors read and approved the final manuscript.

\section{COMPETING INTERESTS}

Authors declare that there were no competing interests.

\section{REFERENCES}

1. Aldegs $Y$, Elbarghouthi M, Elsheikh A, Walker G. Effect of solution $\mathrm{pH}$, ionic strength, and temperature on adsorption behavior of reactive dyes on activated carbon. Dyes and Pigments. 2008;77(1):16-23. <DOI >.

2. Royer B, Cardoso NF, Lima EC, Macedo TR, Airoldi C. A useful organofunctionalized layered silicate for textile dye removal. Journal of Hazardous Materials. 2010 Sep;181(1-3):366-74. <DOI $>$.

3. Memon FN, Memon S. Sorption and Desorption of Basic Dyes from Industrial Wastewater Using Calix[4]arene Based Impregnated Material. Separation Science and Technology. 2015 May 24;50(8):1135-46. $\leq \mathrm{DOI}>$.

4. Rangabhashiyam S, Anu N, Selvaraju N. Sequestration of dye from textile industry wastewater using agricultural waste products as adsorbents. Journal of Environmental Chemical Engineering. 2013 Dec;1(4):629-41. <DOI>.

5. Bello O, Bello I, Adegoke K. Adsorption of dyes using different types of sand: A review. South Afr J Chem. 2013;66:117-29. $\leq$ URL $>$.

6. Malik PK, Saha SK. Oxidation of direct dyes with hydrogen peroxide using ferrous ion as catalyst. Separation and Purification Technology. 2003 Jun;31(3):241-50. <DOI $>$.

7. Gupta VK, Jain R, Mittal A, Mathur M, Sikarwar S. Photochemical degradation of the hazardous dye Safranin-T using TiO2 catalyst. Journal of Colloid and Interface Science. 2007 May;309(2):464-9. <DOI>. 
8. Fan L, Zhou $Y$, Yang $W$, Chen G, Yang $F$. Electrochemical degradation of aqueous solution of Amaranth azo dye on ACF under potentiostatic model. Dyes and Pigments. 2008;76(2):440-6. <DOI $>$.

9. Sachdeva S, Kumar A. Preparation of nanoporous composite carbon membrane for separation of rhodamine B dye. Journal of Membrane Science. 2009 Mar 5;329(12):2-10. $\leq \mathrm{DOI}>$.

10. Saheed IO, Adekola FA, Olatunji GA. Sorption study of methylene blue on activated carbon prepared from Jatropha curcas and Terminalia catappa seed coats. Journal of the Turkish Chemical Society, Section A: Chemistry. 2016 Dec 7;4(1):375-375. <DOI>.

11. Inyinbor AA, Adekola FA, Olatunji GA. Adsorption of Rhodamine $B$ dye from aqueous solution on Irvingia gabonensis biomass: Kinetics and thermodynamics studies. SAfr.j.chem [Internet]. 2015 [cited 2022 Jan 11];68. $\leq$ DOI $>$.

12. Azeez S, Adekola F. Sorption of 4-Nitroaniline on Activated Kaolinitic Clay and Jatropha curcas Activated Carbon in Aqueous Solution. Jordan J Chem. 2021;11(2):130-49. $\leq$ URL $>$.

13. Malik PK. Dye removal from wastewater using activated carbon developed from sawdust: adsorption equilibrium and kinetics. Journal of Hazardous Materials. 2004 Sep;113(1-3):81-8. <DOI 2 .

14. Webb DB, editor. A Guide to species selection for tropical and sub-tropical plantations. 2nd ed., rev. Oxford: Unit of Tropical Silviculture, Commonwealth Forestry Institute, University of Oxford; 1984. 256 p. (Tropical forestry papers). ISBN: 978-0-85074-068-4.

15. Alam Z, Muyibi SA, Toramae J. Statistical optimization of adsorption processes for removal of 2,4dichlorophenol by activated carbon derived from oil palm empty fruit bunches. Journal of Environmental Sciences. 2007 Jan;19(6):674-7. <DOI>.

16. Sudamalla $P$, Saravanan $P$, Matheswaran $M$. Optimization of operating parameters using response surface methodology for adsorption of crystal violet by activated carbon prepared from mango kernel. Environ Res. 2012;22(1):1-7.

17. Ani JU, Okoro UC, Aneke LE, Onukwuli OD, Obi IO, Akpomie KG, et al. Application of response surface methodology for optimization of dissolved solids adsorption by activated coal. Appl Water Sci. 2019 Apr;9(3):60. <DOI $>$.

18. Nwabanne J, Igbokwe P. Application of response surface methodology for preparation of activated carbon from palmyra palm nut. New York Sci J. 2012;5(9):1825.

19. Fu JF, Zhao YQ, Xue XD, Li WC, Babatunde AO. Multivariate-parameter optimization of acid blue-7 wastewater treatment by $\mathrm{Ti} / \mathrm{TiO} 2$ photoelectrocatalysis via the Box-Behnken design. Desalination. 2009 Jul;243(1-3):42-51. <DOI>.

20. Meilgaard M, Civille GV, Carr BT. Sensory evaluation techniques. 3rd ed. Boca Raton, Fla: CRC Press; 1999.
387 p. ISBN: 978-0-8493-0276-3.

21. Amuda OS, Olayiwola AO, Alade AO, Farombi AG, Adebisi SA. Adsorption of Methylene Blue from Aqueous Solution Using Steam-Activated Carbon Produced from Lantana camara Stem. JEP. 2014;05(13):1352-63. $\leq$ DOI $>$.

22. Tangjuank S, Insuk N, Tontrakoon J, Udeye V. Adsorption of lead (II) and cadmium (II) ions from aqueous solutions by adsorption on activated carbon prepared from cashew nut shells. World Academy of Science, Engineering and Technology. 2009;52:110-6.

23. Oyekanmi AA, Ahmad A, Hossain K, Rafatullah $M$. Adsorption of Rhodamine $B$ dye from aqueous solution onto acid treated banana peel: Response surface methodology, kinetics and isotherm studies. Rittschof $D$, editor. PLOS ONE. 2019 May 15;14(5):e0216878. $\leq$ DOI $>$.

24. Azeez S, Adekola F. Kinetics and Thermodynamics of Sorption of 4-Nitrophenol on Activated Kaolinitic Clay and Jatropha Curcas Activated Carbon from Aqueous Solution. Pak J Anal Environ Chem. 2016;17(1):93-105. $\leq \mathrm{URL}>$.

25. Abdolrahimi N, Tadjarodi A. Adsorption of Rhodamine-B from Aqueous Solution by Activated Carbon from Almond Shell. Proceedings. 2019 Nov 14;41(1):51. $\leq \mathrm{DOI}>$.

26. Adekola F, Inyinbor A, Olatunji G. EDTA Modified Irvingia gabonensis: An Efficient Bioresource Material for the Removal of Rhodamine B. Pakistan Journal of Analytical \& Environmental Chemistry. 2015;16(2):10. $\leq \mathrm{URL}>$.

27. Postai DL, Demarchi CA, Zanatta F, Melo DCC, Rodrigues CA. Adsorption of rhodamine $B$ and methylene blue dyes using waste of seeds of Aleurites Moluccana, a low cost adsorbent. Alexandria Engineering Journal. 2016 Jun;55(2):1713-23. <DOI $>$.

28. Prasad AL, Santhi T. Adsorption of hazardous cationic dyes from aqueous solution onto Acacia nilotica leaves as an eco friendly adsorbent. Sustainable Environment Research. 2012;22(2):113-22.

29. Mehrizad A. Adsorption studies of some phenol derivatives onto Ag-cuttlebone nanobiocomposite: modeling of process by response surface methodology.

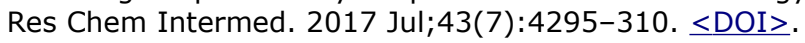

30. Hameed BH, Mahmoud DK, Ahmad AL. Equilibrium modeling and kinetic studies on the adsorption of basic dye by a low-cost adsorbent: Coconut (Cocos nucifera) bunch waste. Journal of Hazardous Materials. 2008 Oct; 158(1):65-72. $\leq$ DOI $>$.

31. Rahman N, Nasir M. Application of Box-Behnken design and desirability function in the optimization of $\mathrm{Cd}(\mathrm{II})$ removal from aqueous solution using poly(ophenylenediamine)/hydrous zirconium oxide composite: equilibrium modeling, kinetic and thermodynamic studies. Environ Sci Pollut Res. 2018 Sep;25(26):2611434. $\leq \mathrm{DOI}>$.

32. Etim UJ, Umoren SA, Eduok UM. Coconut coir dust as 
a low cost adsorbent for the removal of cationic dye from aqueous solution. Journal of Saudi Chemical Society. 2016 Sep;20:S67-76. $\leq$ DOI $>$.

33. Yuh-Shan $\mathrm{H}$. Citation review of Lagergren kinetic rate equation on adsorption reactions. Scientometrics. 2004;59(1):171-7. <DOI>.

34. Idris $M N$, Ahmad ZA, Ahmad MA. Adsorption equilibrium of malachite green dye onto rubber seed coat based activated carbon. International Journal of Basic \& Applied Sciences. 2011;11(3):38-43.

35. Rathour R, Das $P$, Aikat K. Microwave-assisted synthesis of graphene and its application for adsorptive removal of malachite green: thermodynamics, kinetics and isotherm study. Desalination and Water Treatment. 2016 Apr 2;57(16):7312-21. <DOI>. 